\section{Rapid immunochromatographic tests for the diagnosis of dengue: a systematic review and meta-analysis}

\author{
Testes imunocromatográficos rápidos para o \\ diagnóstico da dengue: uma revisão \\ sistemática e metanálise
}

\author{
Pruebas inmunocromatográficas rápidas para \\ la diagnosis del dengue: una revisión \\ sistemática y metaanálisis
}

\begin{abstract}
Dengue is an important arthropod-borne viral disease in terms of morbidity, mortality, economic impact and challenges in vector control. Benchmarks are expensive, time consuming and require trained personnel. Preventing dengue complications with rapid diagnosis has been based on the testing of easy-to-perform optimized immunochromatographic methods (ICT). This is a systematic meta-analysis review of the diagnostic accuracy of IgA, NS1, IgM and/or IgG ICT studies in suspected cases of acute or convalescent dengue, using a combination of RT-PCR, ELISA NS1, IgM IgG or viral isolation as a reference standard. This protocol was registered in PROSPERO (CRD42014009885). Two pairs of reviewers searched the PubMed, BIREME, Science Direct, Scopus, Web of Science, Ovid MEDLINE JBrigs, SCIRUS and EMBASE databases, selected, extracted, and quality-assessed by QUADAS 2. Of 3,783 studies, we selected 57, of which 40 in meta-analyses according to the analyte tested, with high heterogeneity (I2 > 90\%), as expected for diagnostic tests. We detected higher pooled sensitivity in acute phase IgA (92.8\%) with excellent (90\%) specificity. ICT meta-analysis with NS1/IgM/IgG showed 91\% sensitivity and 96\% specificity. Poorer screening performance was for $\operatorname{IgM} / \operatorname{IgG} I C T$ (sensitivity = 56\%). Thus, the studies with NS $1 / \operatorname{Ig} M / \operatorname{IgG} I C T$ showed the best combined performance in the acute phase of the disease.
\end{abstract}

Dengue; Diagnosis; Sensitivity and Specificity; Systematic Review;

Meta-Analysis
Verónica Elizabeth Mata 1

Carlos Augusto Ferreira de Andrade 1

Sonia Regina Lambert Passos 1

Yara Hahr Marques Hökerberg 1

Levy Vilas Boas Fukuoka 1

Suzana Alves da Silva 2

doi: 10.1590/0102-311X00225618

\section{Correspondence}

V. E. Mata

Fundação Oswaldo Cruz.

Av. Brasil 4365, Rio de Janeiro, RJ 21040-900, Brasil.

veronica.elizabeth.mata@gmail.com

1 Fundação Oswaldo Cruz, Rio de Janeiro, Brasil.

2 Hospital do Coração, São Paulo, Brasil. 


\section{Introduction}

Dengue is an acute viral disease caused by a virus transmitted mainly by Aedes aegypti. This arthropodborne flavivirus has four distinct serotypes: DENV-1, DENV-2, DENV-3, and DENV-4, which constitute an antigen complex of the Flavivirus genus, Flaviviridae family 1.

Dengue virus is present in more than 100 countries of the Asia-Pacific, Americas, Middle East, and Africa 2,3,4, with 3 billion people (40\% of the world population) at risk of infection in tropical and subtropical regions, with 50 to 100 million infections per year 2,4,5. It is an important arthropod-borne viral disease in terms of human morbidity, mortality and economic impact. Many challenges remain concerning disease control and prevention programs based on vector reproduction and elimination, clinical aspects and pathogenesis 5 .

The clinical presentation of dengue infection is highly unspecific varying according to the circulating serotype 5. Differential diagnosis of dengue in urban areas of large metropolises in Latin America, where malaria is not endemic, includes influenza 6,7. In Brazil, since 2013 8, also zika and chikungunya are co-circulating ${ }^{9}$, making the diagnosis on a clinical basis unreliable. Thus, diagnostic optimization for adequate clinical management to prevent complications caused by dengue requires better, easier and more efficient rapid tests with good accuracy for case management during the earlier state of infection.

Among the rapid tests, those using the immunochromatographic technique (ICT) to detect the presence of nonstructural protein 1 (NS1) play an important role in early diagnosis of dengue fever (up to seven days from the onset of symptoms) 10. Reference standards such as virus isolation, PCR or PRNT have the great disadvantages of being laborious, time consuming, require specific reagents, equipment, trained personnel and are high cost. ELISA IgM/IgG has been important for health surveillance and distinguishes between primary and secondary infectious in cases previously confirmed by RT-PCR or virus isolation but presents cross-reactivity with other members of the Flaviviradidae family 6.

We found five systematic reviews with meta-analysis on the subject 4,6,11,12,13. Alagarasu et al. 11 included only publications on IgA ICT. Another meta-analysis included nine studies on NS1 ICT 4 and the systematic review by Blacksell et al. 6 assessed a single commercial test (Panbio ICT - Abbott Laboratories) in 11 studies, showing wide variability between them. These reviews point out the high specificity of the ICT, but with heterogeneous sensitivities, requiring a critical assessment that includes the various types of ICT and brands available on the market as well as their evaluation in acute and convalescent samples. In fatal cases, NS1 strip showed better sensitivity (78.3\%) than ELISA NS1 10.

A recent systematic review 12 on the economic impact of dengue's ICT favored a relatively obsolete diagnostic strategy based on IgM Panbio for acute cases. However, it identified only two studies, one using primary observational data 14 and the other, a simulation modeling design 15 .

In children, when it could be difficult to access blood samples, some studies were carried out in saliva and urine 16,17. Muso et al. ${ }^{17}$ suggested that only $19 \%$ of the studies detected zika virus in saliva, concluding that it could not replace blood tests. In a recent review, Colonetti et al. 18 included three studies for dengue diagnosis evaluating salivary IgM, which provided sensitivity of $86 \%$ and specificity of $93 \%$. Two included studies evaluating salivary IgA showed a pooled sensitivity of $69 \%$ and a pooled specificity of $98 \%$. Despite these results and the low methodological quality of the studies included in the meta-analysis, the authors concluded that it is still soon to claim that IgA is better than IgM to diagnose dengue 18 .

This study aimed to review the literature on the accuracy of ICT using as the reference test any type of PCR, ELISA, or virus isolation, in suspected dengue cases with up to seven days since the onset of fever for NS1 ICT and with no restriction on the days of fever for IgA, IgM/IgG, or NS1/ IgM/IgG ICT. 


\section{Methods}

This was a systematic literature review of observational diagnostic studies reported in the Preferred Reporting Items for Systematic Reviews and Meta-Analyses (PRISMA) statement 19. The protocol was previously registered on the site PROSPERO number CRD42014009885.

\section{Data sources and search strategy}

The research question was: Are point of care immunochromatographic tests accurate for early detection of dengue infection? Does the test performance vary according to age, sex, dengue serotype, reference tests or whether it is a primary or secondary infection, acute or convalescent phases? These questions guided the eligibility criteria expressed in the PICO (Patient, Intervention, Comparison and Outcomes) format:

Population: blood/serum or plasma samples from patients with febrile illness suspected of dengue with up to seven days of fever in the acute phase of the disease and with no time limit in the convalescent phase;

Intervention (index tests): ICTs with detection of IgA, NS1, IgM/IgG, or NS1/IgM/IgG, read within 60 minutes;

Comparator (reference standard): PCR, ELISA NS1 or IgM, virus isolation, or a combination of two or three of these;

Outcome (diagnostic parameters): sensitivity, specificity, likelihood ratios, and positive and negative predictive values in ICTs for dengue, besides the information on time and effect measures, according to the case.

We excluded articles that: use inappropriate reference tests, index test limited to the detection of IgG antibodies or that takes more than 60 minutes to perform, incomplete description or partial examination of sample, small sample size or insufficient data to calculate accuracy parameters.

In case of doubt we directly contacted the authors. We did not limit the search based on study design nor on language of publication.

Two researchers conducted the searches up to October 2019 for journal articles or congress proceedings publications since inception in MEDLINE via PubMed, Science Direct, Scopus, Web of Science, Ovid MEDLINE JBrigs, SCIRUS, BIREME and EMBASE, with no restriction on language or study design. We also searched gray literature using Google Scholar. Our search strategy in MEDLINE via PubMed employed the keywords: ("dengue/diagnosis"[MeSH Terms]) AND (diagnostic reagents and test kits [MeSH Terms]), generating the following strategy: "humans"[MeSH Terms] AND ("Dengue" OR "Dengue Virus") AND (sensitiv*[Title/Abstract] OR specificity[Title/Abstract] OR "sensitivity and specificity"[Mesh Terms] OR "Reference Values"[Mesh] OR diagnosis*[Title/ Abstract] OR diagnosis[Mesh] OR diagnosis[Subheading]) AND ((“"Serologic Tests” OR Immunoassay OR "Reagent Kits, Diagnostic") AND (Bedside OR Rapid)) OR "Point-of-Care Systems" OR "NS1" OR "NS-1" OR "Viral nonstructural proteins" OR Immunochromatogra* OR Immunochromatography OR bioeasy OR bioline OR bioline OR panbio OR core OR ag-strip OR strip OR Duo OR biorad OR "Reagent Strips"). We used equivalent strategies in the other databases and employed Zotero Standalone 4.0 for Windows (https://www.zotero.org/) in the search and filing of references.

\section{Study selection}

Initially, three pairs of reviewers (V.E.M./C.A.F.A., L.V.B.F./S.R.L.P., and Y.H.M.H./S.R.L.P.) independently selected the study abstracts. We held consensus meetings, and in case of disagreement, a third reviewer external to the pair judged the article's relevance. In the second stage, pairs of reviewers (V.E.M./C.A.F.A., V.E.M./S.R.L.P., and Y.H.M.H./S.R.L.P.) read the full-text articles, also independently. Disagreements arising in the consensus meetings of the respective pairs were also resolved with a third external reviewer. 


\section{Data extraction and assessment of risk of bias}

We designed a standardized form to extract the following variables by the pairs of reviewers: study design, commercial test names, test manufacturing countries, type of detection used, reference test used, number of study participants, number of confirmed dengue cases, non-dengue cases, measures of accuracy, virus serotype, and time since onset of fever.

We used the Quality Assessment of Diagnostic Accuracy Studies (QUADAS 2) 20 to assess the quality of the selected articles, risk of bias, and applicability. The tool consists of 14 items distributed across four domains that assess patient selection, index test, reference test, flow and timing.

\section{Data synthesis and analysis}

We used the "reference standard" defined in each selected study for comparison with the index test to determine the true-positive (TP), false-positive (FP), false-negative (FN), and true-negative (TN) values. Diagnostic accuracy, sensitivity (Sn), specificity (Sp), positive predictive value (PPV), negative predictive value (NPV), positive (LR+) and negative likelihood ratios (LR-), diagnostic odds ratio (DOR). We estimated positive (PP+) and negative post-test probabilities (PP-) in scenarios of $25 \%$, $50 \%$, and $75 \%$ prevalence.

For each ICT (IgA, NS1, IgM/IgG, NS1/IgM/IgG), we performed a meta-analysis for each measure of diagnostic accuracy listed above, with the respective 95\% confidence intervals (95\%CI). The analyses were performed with the Winpepi (http://www.brixtonhealth.com/pepi4windows.html) and Stata XIV (https://www.stata.com) packages using the MIDAS command (Meta-analytical Integration of Diagnostic Accuracy Studies) performing the bivariate mixed-effects binary regression modeling framework. Meta-analyses were conducted according to the different analytes and/or brands.

We calculated the I2 statistic to detect significant overall and inter-subgroup heterogeneity 21 . We considered $\mathrm{I}^{2}$ values greater than $50 \%$ as high evidence of heterogeneity in data. In the presence of I 2 point estimate higher than 50\%, we performed meta-analysis using random effects model 22 .

We analyzed study heterogeneity graphically and through the I2 test. We explored possible causes of clinical heterogeneity between studies through subgroup analyses: disease phase (acute or convalescent), by the most extensively assessed brand name, and overall quality of studies according dimensions of QUADAS 2 (low versus high or unclear risk of bias) 20.

Assessment of publication bias used the Deeks graph, where p-value $<0.05$ was considered significant 23 .

\section{Results}

\section{Characteristics of included studies}

The initial search identified 3,791 publications. After removing duplicates, we reviewed 3,783 abstracts, and selected 108 articles for reading the full-texts, of which 57 were selected for this review (Figure 1). The studies assessed multiple ICT brand tests with different analytes: five assessed IgA 24,25,26,27,28, 21 NS1 10,27,29,30,31,32,33,34,35,36,37,38,39,40,41,42,43,44,45,46,47, 12 IgM/IgG 27,34,48,49,50,51,52,53,54, 55,56,57, and $25 \mathrm{NS} 1 / \operatorname{IgM} / \operatorname{IgG} 29,36,37,40,46,58,59,60,61,62,63,64,65,66,67,68,69,70,71,72,73,74,75,76,77$ (Table 1). The total number exceeds since some studies evaluated more than one ICT brand tests and type of analyte. Those articles evaluating NS1/IgM/IgG estimated not only the accuracy parameters for the three analytes, but also for each analyte separately.

Although planned, stratified analysis was not available in original studies, except for different analytes.

The 57 studies were performed mainly in Asia (33; 57.9\%) and the Americas (18; 31.6\%), only one in Oceania and mostly (94.1\%) published in English.

The included studies analyzed 29 ICTs, using as the reference tests RT-PCR, real-time PCR, seminested PCR, NS1 ELISA, IgM ELISA, IgG ELISA, IgM antibody capture enzyme-linked immuno- 


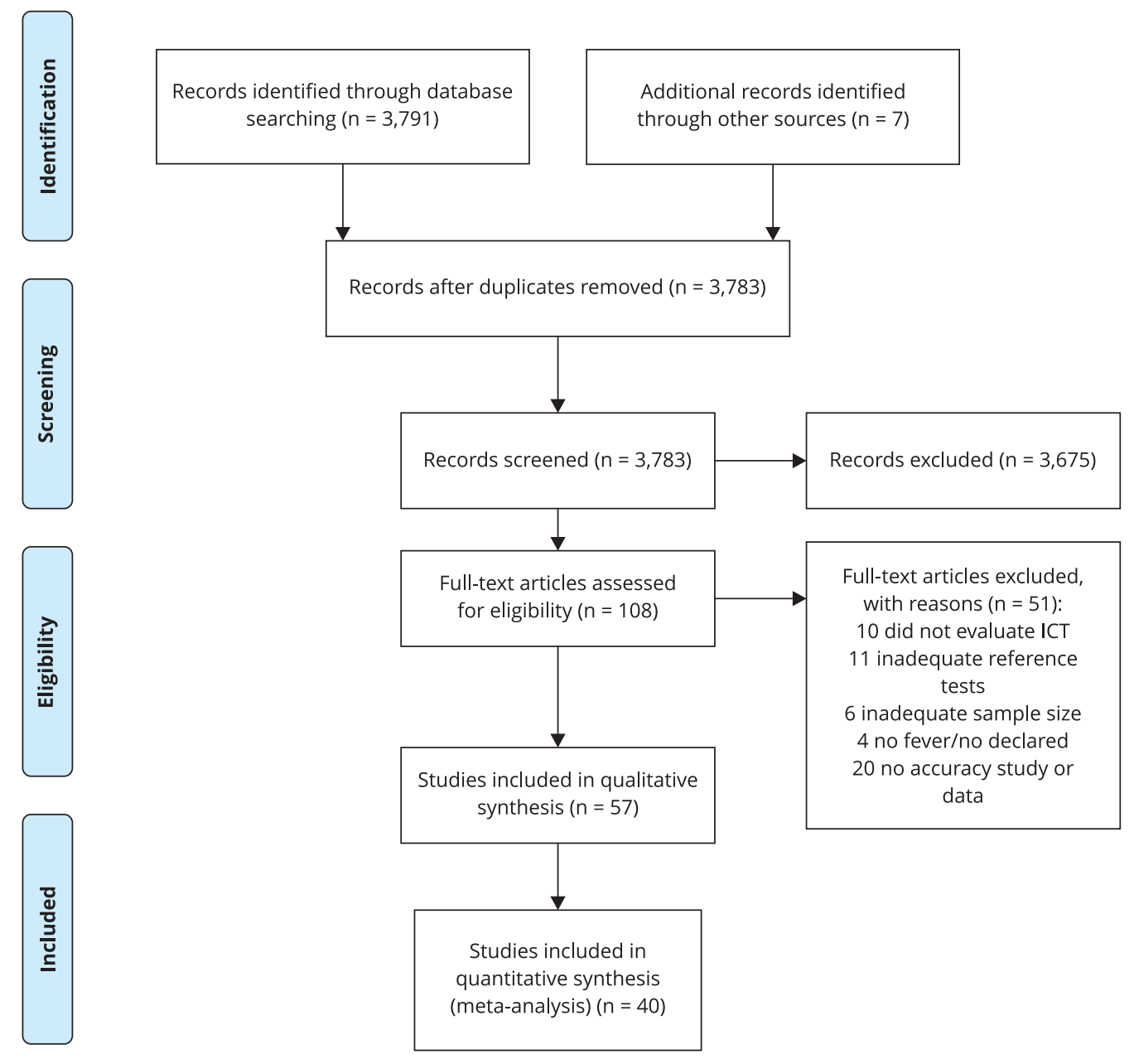

sorbent assay (MAC ELISA IgM), IgG antibody capture enzyme-linked immunosorbent assay (GAC ELISA IgG), or virus isolation (Table 1).

\section{Quality assessment of the studies}

According to the assessment of methodological quality conducted with the QUADAS 2 tool, of the 57 included studies, only six 29,30,38,39,69,78 did not show risk of bias, and 25 (43.8\%) of the them showed high risk of bias regarding the patient selection process (Figure 2), mainly due to case-control design. Ten of them showed high risk of bias concerning flow and timing, mainly for excluding patients from analysis or for adopting inappropriate intervals between index and reference tests. Concerning reference standard, 31 studies were unclear and three showed high risk of bias, mainly due to not informing about blinding.

However, we did not find any major conflicts that could compromise applicability in relation to patients included, index or reference tests in these studies from those targeted by our review questions. 
Mata VE et al.

Table 1

Characteristics and accuracy of rapid immunochromatographic tests (ICT) of the included studies.

\begin{tabular}{|c|c|c|c|c|c|c|c|c|c|c|}
\hline ICT & Study (year) & Country & $\begin{array}{l}\text { Design } \\
\text { 1ary:2nd } \\
\text { infection }\end{array}$ & $\begin{array}{c}\mathrm{N} \\
\text { (dengue } \\
\text { cases) }\end{array}$ & $\begin{array}{c}\text { Sn \% } \\
(95 \% \mathrm{Cl})\end{array}$ & $\begin{array}{c}\text { Sp \% } \\
(95 \% \mathrm{Cl})\end{array}$ & $\begin{array}{c}\text { PPV \% } \\
(95 \% \mathrm{Cl})\end{array}$ & $\begin{array}{l}\text { NPV \% } \\
(95 \% \mathrm{Cl})\end{array}$ & $\operatorname{DENV}(\mathrm{n})$ & $\begin{array}{l}\text { Reference } \\
\text { standard }\end{array}$ \\
\hline \multicolumn{11}{|l|}{ IgA } \\
\hline \multirow[t]{5}{*}{ ASSURE } & $\begin{array}{c}\text { Ahmed et al. } 24 \\
\text { (2010) }\end{array}$ & Bangladesh & $\begin{array}{l}\text { CC } \\
1: 1\end{array}$ & 424 (179) & $\begin{array}{c}86.0 \\
(80.1-90.8)\end{array}$ & $\begin{array}{c}99.2 \\
(97.1-99.9)\end{array}$ & $\begin{array}{c}98.7 \\
(95.2-99.6)\end{array}$ & $\begin{array}{c}90.7 \\
(86.5-93.5)\end{array}$ & - & $\begin{array}{c}\text { ELISA NS1/ } \\
\text { IgM/IgG }\end{array}$ \\
\hline & & & Conval. & & $\begin{array}{c}99.4 \\
(96.9-99.9)\end{array}$ & $\begin{array}{c}92.0 \\
(73.9-98.8)\end{array}$ & $\begin{array}{c}98.9 \\
(96.1-99.8)\end{array}$ & $\begin{array}{c}95.8 \\
(78.8-99.3)\end{array}$ & & \\
\hline & $\begin{array}{c}\text { Tan et al. } 28 \\
\text { (2011) }\end{array}$ & Singapore & $\begin{array}{c}\mathrm{CC} \\
-\end{array}$ & $914(233)$ & $\begin{array}{c}86.7 \\
(81.7-90.8)\end{array}$ & $\begin{array}{c}86.1 \\
(83.2-88.6)\end{array}$ & $\begin{array}{c}68.0 \\
(62.4-73.3)\end{array}$ & $\begin{array}{c}94.9 \\
(92.9-95.6)\end{array}$ & - & $\begin{array}{c}\text { ELISA IgM/lgG } \\
\text { RT-PCR }\end{array}$ \\
\hline & $\begin{array}{l}\text { Hernández et } \\
\text { al. } 26 \text { (2012) }\end{array}$ & Mexico & $\begin{array}{c}\text { CS } \\
5: 1 \text { (acute) }\end{array}$ & $225(172)$ & $\begin{array}{c}61.1 \\
(53.6-68.0)\end{array}$ & $\begin{array}{c}86.8 \\
(75.2-93.5)\end{array}$ & $\begin{array}{c}93.8 \\
(88.4-96.7)\end{array}$ & $\begin{array}{c}40.7 \\
(35.6-46.0)\end{array}$ & $\begin{array}{l}1(103) \\
2(69)\end{array}$ & $\begin{array}{c}\text { RT-PCR } \\
\text { ELISA NS1/ } \\
\text { IgM/IgG }\end{array}$ \\
\hline & $\begin{array}{l}\text { Naz et al. } 27 \\
\text { (2014) }\end{array}$ & Pakistan & $\begin{array}{l}\text { CS } \\
1: 1\end{array}$ & $184(142)$ & $\begin{array}{c}85.2 \\
(78.3-90.6)\end{array}$ & $\begin{array}{c}81.0 \\
(65.9-91.4)\end{array}$ & $\begin{array}{c}93.8 \\
(88.2-97.3)\end{array}$ & $\begin{array}{c}61.8 \\
(47.7-74.6)\end{array}$ & - & ELISA IgM/IgM \\
\hline $\begin{array}{l}\text { Dengue Rapid } \\
\text { Test }\end{array}$ & $\begin{array}{l}\text { Hartono \& Sari } \\
\quad 25 \text { (2012) }\end{array}$ & - & CS & $100(70)$ & $\begin{array}{c}82.9 \\
(72.4-89.9)\end{array}$ & $\begin{array}{c}73.3 \\
(55.6-85.8)\end{array}$ & $\begin{array}{c}87.9 \\
(80.0-92.9)\end{array}$ & $\begin{array}{c}64.7 \\
(51.3-76.1)\end{array}$ & - & $\begin{array}{c}\text { ELISA NS1/ } \\
\text { IgM/IgG }\end{array}$ \\
\hline \multicolumn{11}{|l|}{ NS1 } \\
\hline \multirow[t]{9}{*}{ Bio-Rad } & $\begin{array}{l}\text { Dussart et } \\
\text { al. } 32 \text { (2008) }\end{array}$ & Guiana & $\begin{array}{l}\mathrm{CC} \\
1: 0\end{array}$ & $\begin{array}{l}320(222) \\
\text { Read. 15' } \\
\text { Read. 30' }\end{array}$ & $\begin{array}{c}76.1 \\
(70.7-80.8) \\
77.6 \\
(72.3-82.1)\end{array}$ & $\begin{array}{c}100.0 \\
(92.6-100.0) \\
100.0 \\
(92.6-100.0)\end{array}$ & $\begin{array}{c}100.0 \\
(98.2-100.0) \\
100.0 \\
(98.3-100.0)\end{array}$ & $\begin{array}{c}42.5 \\
(33.2-52.1) \\
44.0 \\
(34.5-53.9)\end{array}$ & $\begin{array}{l}1(33) \\
2(42) \\
3(101) \\
4(46)\end{array}$ & $\begin{array}{c}\text { RT-PCR } \\
\text { Viral isolation }\end{array}$ \\
\hline & $\begin{array}{l}\text { Zainah et al. } 47 \\
\text { (2009) }\end{array}$ & Spain & $\mathrm{CC}$ & $533(314)$ & $\begin{array}{c}90.4 \\
(86.7-93.2)\end{array}$ & $\begin{array}{c}99.5 \\
(97.5-99.9)\end{array}$ & $\begin{array}{c}99.6 \\
(97.9-99,9)\end{array}$ & $\begin{array}{c}87.9 \\
(83.2-91.3)\end{array}$ & - & $\begin{array}{c}\text { ELISA NS1/IgG } \\
\text { Viral isolation } \\
\text { RT-PCR }\end{array}$ \\
\hline & $\begin{array}{l}\text { Hang et al. } 35 \\
\qquad(2009)\end{array}$ & Vietnam & Cohort & $138(125)$ & $\begin{array}{c}72.8 \\
(64.4-79.8)\end{array}$ & $\begin{array}{c}100.0 \\
(77.2-100.0)\end{array}$ & $\begin{array}{c}100.0 \\
(96.7-100.0)\end{array}$ & $\begin{array}{c}27.7 \\
(15.6-42.6)\end{array}$ & $\begin{array}{c}1(63) \\
2(20) \\
3(25) \\
4(3)\end{array}$ & $\begin{array}{c}\text { ELISA IgM/IgG } \\
\text { RT-PCR }\end{array}$ \\
\hline & $\begin{array}{l}\text { Ramirez et } \\
\text { al. } 44 \text { (2009) }\end{array}$ & Venezuela & $\mathrm{CC}$ & 147 (87) & $\begin{array}{c}67.8 \\
(57.4-76.7)\end{array}$ & $\begin{array}{c}96.7 \\
(88.6-99.1)\end{array}$ & $\begin{array}{c}96.7 \\
(89.6-99.0)\end{array}$ & $\begin{array}{c}67.4 \\
(60.4-73.8)\end{array}$ & $\begin{array}{l}1(21) \\
2(23) \\
3(23) \\
4(20)\end{array}$ & $\begin{array}{c}\text { RT-PCR } \\
\text { Viral isolation } \\
\text { ELISA IgM }\end{array}$ \\
\hline & $\begin{array}{c}\text { Chaiyaratan et } \\
\text { al. } 31 \text { (2009) }\end{array}$ & $\begin{array}{l}\text { Marshall } \\
\text { Islands }\end{array}$ & $\mathrm{CC}$ & 104 (89) & $\begin{array}{c}98.9 \\
(96.8-100)\end{array}$ & $\begin{array}{c}90.6 \\
(85.6-95.7)\end{array}$ & $\begin{array}{c}99.0 \\
(96.2-99.7)\end{array}$ & $\begin{array}{c}90.5 \\
(69.8-96.8)\end{array}$ & - & $\begin{array}{l}\text { ELISA NS1/ } \\
\text { IgM/lgG }\end{array}$ \\
\hline & $\begin{array}{l}\text { Shu et al. } 45 \\
\text { (2009) (blood) }\end{array}$ & $\begin{array}{l}8 \text { Asian } \\
\text { countries }\end{array}$ & CS & $850(22)$ & $\begin{array}{c}77.3 \\
(56.6-89.9)\end{array}$ & $\begin{array}{c}100.0 \\
(99.5-100.0)\end{array}$ & 100.0 & 99.4 & $\begin{array}{l}1(9) \\
2(3) \\
3(5)\end{array}$ & $\begin{array}{c}\text { RT-PCR } \\
\text { ELISA IgM/IgG }\end{array}$ \\
\hline & $\begin{array}{l}\text { Lima et al. } 10 \\
\qquad(2010)\end{array}$ & Brazil & $\mathrm{CC}$ & $450(220)$ & $\begin{array}{c}89.6 \\
(84,8-92.9)\end{array}$ & $\begin{array}{c}99.1 \\
(96.9-99.8)\end{array}$ & $\begin{array}{c}99.0 \\
(96.9-99.7)\end{array}$ & $\begin{array}{c}90.8 \\
(87.1-93.6)\end{array}$ & $\begin{array}{l}1(180) \\
2(78) \\
3(28) \\
4(40)\end{array}$ & $\begin{array}{l}\text { Viral isolation } \\
\qquad \text { RT-PCR } \\
\text { ELISA IgM/IgG }\end{array}$ \\
\hline & $\begin{array}{l}\text { Pok et al. } 43 \\
(2010)\end{array}$ & Singapore & Cohort & $112(52)$ & $\begin{array}{c}76.9 \\
(63.9-86.3)\end{array}$ & $\begin{array}{c}100.0 \\
(94.0-100.0)\end{array}$ & 100.0 & 83.3 & $\begin{array}{c}1(21) \\
2(23) \\
3(17) \\
4(2)\end{array}$ & $\begin{array}{c}\text { ELISA IgM/lgG } \\
\text { Paired }\end{array}$ \\
\hline & & & CS & 209 (109) & $\begin{array}{c}78.9 \\
(70.0-86.1)\end{array}$ & $\begin{array}{c}99.0 \\
(94.6-99.9)\end{array}$ & $\begin{array}{c}98.9 \\
(96.6-100)\end{array}$ & $\begin{array}{c}81.2 \\
(73.1-88.2)\end{array}$ & - & RNA viral \\
\hline
\end{tabular}

(continues) 


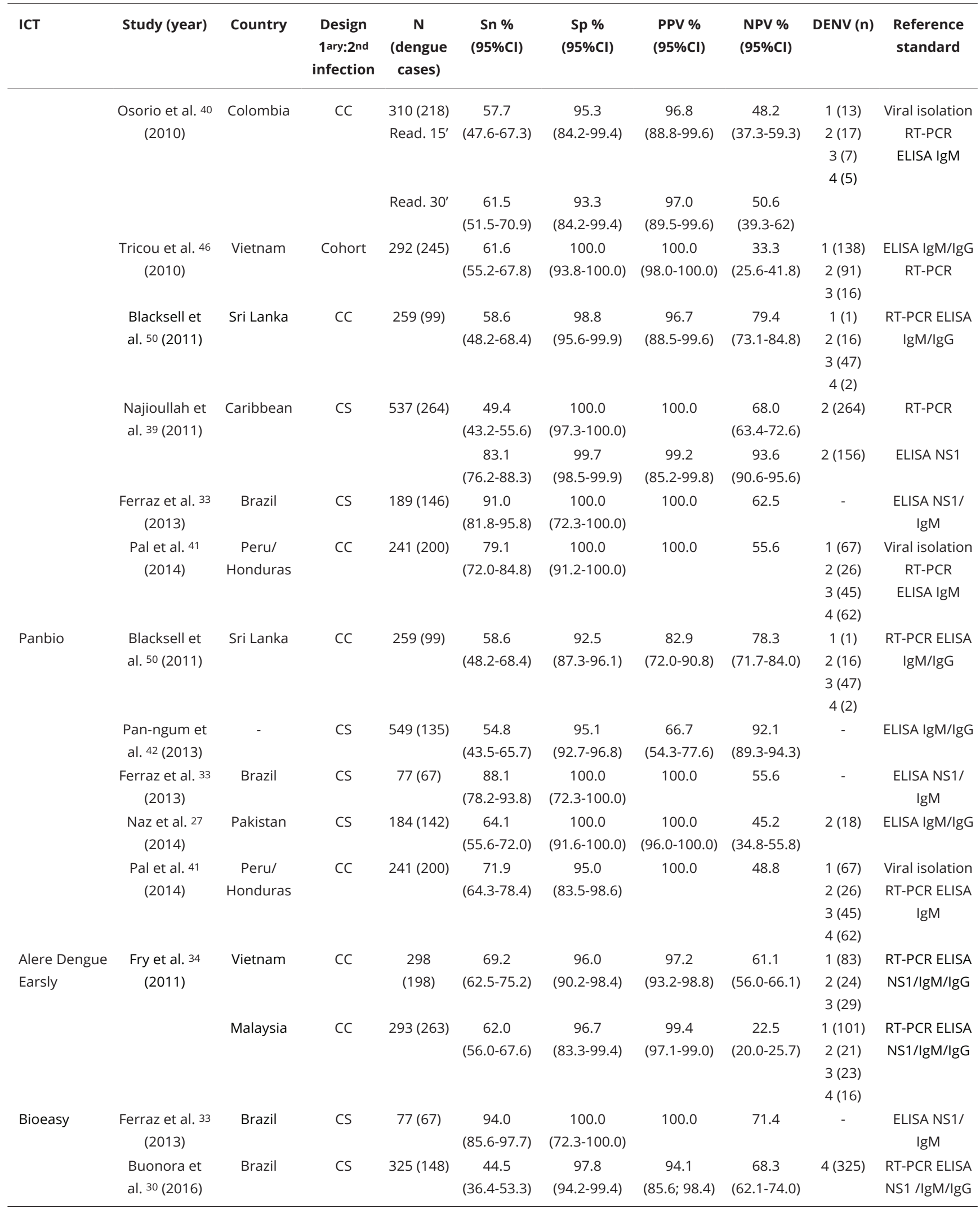

(continues) 
Table 1 (continued)

\begin{tabular}{|c|c|c|c|c|c|c|c|c|c|c|}
\hline ICT & Study (year) & Country & $\begin{array}{c}\text { Design } \\
\text { 1ary:2nd } \\
\text { infection }\end{array}$ & $\begin{array}{c}\mathrm{N} \\
\text { (dengue } \\
\text { cases) }\end{array}$ & $\begin{array}{c}\text { Sn \% } \\
(95 \% \mathrm{Cl})\end{array}$ & $\begin{array}{c}\text { Sp \% } \\
(95 \% \mathrm{CI})\end{array}$ & $\begin{array}{l}\text { PPV \% } \\
(95 \% \mathrm{Cl})\end{array}$ & $\begin{array}{l}\text { NPV \% } \\
(95 \% \mathrm{CI})\end{array}$ & $\operatorname{DENV}(n)$ & $\begin{array}{l}\text { Reference } \\
\text { standard }\end{array}$ \\
\hline & \multirow[t]{4}{*}{$\begin{array}{l}\text { Mata et al. } 38 \\
\qquad(2017)\end{array}$} & \multirow[t]{4}{*}{ Brazil } & \multirow[t]{4}{*}{$\begin{array}{l}\text { CS } \\
1: 1\end{array}$} & $\begin{array}{l}144(120) \\
\text { Read. 15' }\end{array}$ & $\begin{array}{c}76.7 \\
(68.0-84.1)\end{array}$ & $\begin{array}{c}87.0 \\
(66.4-97.2)\end{array}$ & $\begin{array}{c}96.7 \\
(90.8-99.3)\end{array}$ & $\begin{array}{c}42.6(28.3- \\
57.8)\end{array}$ & \multirow[t]{4}{*}{$1(105)$} & $\begin{array}{c}\text { RT-PCR ELISA } \\
\text { NS1 (whole } \\
\text { blood) }\end{array}$ \\
\hline & & & & Read. 30' & $\begin{array}{c}78.3 \\
(69.9-85.3)\end{array}$ & $\begin{array}{c}87.5 \\
(67.6-97.3)\end{array}$ & $\begin{array}{c}96.9 \\
(91.2-99.4)\end{array}$ & $\begin{array}{c}44.7 \\
(30.2-59.9)\end{array}$ & & (whole blood) \\
\hline & & & & Read. 15' & $\begin{array}{c}82.2 \\
(74.1-88.6)\end{array}$ & $\begin{array}{c}100.0 \\
(85.8-100.0)\end{array}$ & $\begin{array}{c}100.0 \\
(96.3-100.0)\end{array}$ & $\begin{array}{c}53.3 \\
(37.9-68.3)\end{array}$ & & (serum) \\
\hline & & & & Read. 30' & $\begin{array}{c}84.9 \\
(77.2-90.8)\end{array}$ & $\begin{array}{c}95.8 \\
(78.9-99.9)\end{array}$ & $\begin{array}{c}99.0 \\
(95.4-99.8)\end{array}$ & $\begin{array}{c}56.1 \\
(39.8-71.5)\end{array}$ & & (serum) \\
\hline Inbio & $\begin{array}{l}\text { Pal et al. } 41 \\
\text { (2014) }\end{array}$ & $\begin{array}{l}\text { Peru/ } \\
\text { Honduras }\end{array}$ & CC & $241(200)$ & $\begin{array}{c}76.5 \\
(65.1-85.0)\end{array}$ & $\begin{array}{c}97.4 \\
(86.8-99.6)\end{array}$ & 98.1 & 78.4 & $\begin{array}{l}1(67) \\
2(26) \\
3(45) \\
4(62)\end{array}$ & $\begin{array}{c}\text { Viral isolation } \\
\text { RT-PCR } \\
\text { ELISA IgM }\end{array}$ \\
\hline Asan & $\begin{array}{c}\text { Lee et al. } 37 \\
\text { (2019) }\end{array}$ & Korea & CC & $138(75)$ & $\begin{array}{c}41.3 \\
(29.0-54.4)\end{array}$ & $\begin{array}{c}100.0 \\
(95.2-100.0)\end{array}$ & $\begin{array}{c}100.0 \\
(85.2-100.0)\end{array}$ & $\begin{array}{c}66.9 \\
(62.2-71.4)\end{array}$ & - & $\begin{array}{c}\text { PCR-ELISA } \\
\text { NS1/lgM/lgG }\end{array}$ \\
\hline Asan Ag100 & $\begin{array}{l}\text { Lee et al. } 37 \\
\text { (2019) }\end{array}$ & Korea & CC & $138(75)$ & $\begin{array}{c}42.9 \\
(17.7-71.1)\end{array}$ & $\begin{array}{c}99.2 \\
(95.6-99.9)\end{array}$ & $\begin{array}{c}85.7 \\
(43.7-97.9)\end{array}$ & $\begin{array}{c}93.9 \\
(90.7-96.0)\end{array}$ & - & ELISA IgM \\
\hline Boditech Med & $\begin{array}{l}\text { Lee et al. } 37 \\
\text { (2019) }\end{array}$ & Korea & CC & $138(75)$ & $\begin{array}{c}85.7 \\
(74.6-93.3)\end{array}$ & $\begin{array}{c}92.0 \\
(83.4-97.0)\end{array}$ & $\begin{array}{c}90.0 \\
(80.6-95.1)\end{array}$ & $\begin{array}{c}88.5 \\
(80.7-93.4)\end{array}$ & - & $\begin{array}{c}\text { PCR-ELISA } \\
\text { NS1/lgM/lgG }\end{array}$ \\
\hline \multirow[t]{2}{*}{ SD Bioline } & $\begin{array}{c}\text { Jusoh \& } \\
\text { Shueb } 36 \\
(2017)\end{array}$ & - & CC & $86(36)$ & $\begin{array}{c}88.9 \\
(74.7-95.6)\end{array}$ & $\begin{array}{c}100.0 \\
(92.9-100.0)\end{array}$ & 100.0 & 92.6 & $\begin{array}{l}1(14) \\
2(8) \\
3(2) \\
4(1)\end{array}$ & $\begin{array}{c}\text { RT-PCR ELISA } \\
\text { NS1 }\end{array}$ \\
\hline & $\begin{array}{l}\text { Pal et al. } 41 \\
\text { (2014) }\end{array}$ & $\begin{array}{l}\text { Peru/ } \\
\text { Honduras }\end{array}$ & CC & $241(200)$ & $\begin{array}{c}72.4 \\
(64.8-78.9)\end{array}$ & $\begin{array}{c}100.0 \\
(91.2-100)\end{array}$ & 100.0 & 48.8 & $\begin{array}{l}1(67) \\
2(26) \\
3(45) \\
4(62)\end{array}$ & $\begin{array}{c}\text { Viral isolation } \\
\text { RT-PCR } \\
\text { ELISA IgM }\end{array}$ \\
\hline \multicolumn{11}{|l|}{ IgM/IgG } \\
\hline SD Bioline & $\begin{array}{l}\text { Blacksell et } \\
\text { al. } 29 \text { (2006) }\end{array}$ & Thailand & CC & $491(326)$ & $\begin{array}{c}21.8 \\
(17.4-26.7)\end{array}$ & $\begin{array}{c}98.8 \\
(95.7-99.9)\end{array}$ & $\begin{array}{c}97.3 \\
(90.5-99.7)\end{array}$ & $\begin{array}{c}39.0 \\
(34.3-43.9)\end{array}$ & - & $\begin{array}{c}\text { RT-PCR } \\
\text { ELISA IgM/IgG }\end{array}$ \\
\hline $\begin{array}{l}\text { Panbio } \\
\text { dengue IC }\end{array}$ & $\begin{array}{c}\text { Branch \& } \\
\text { Levett } 51 \\
(1999)\end{array}$ & - & CS & $62(36)$ & $\begin{array}{c}83.9 \\
(72.8-91.0)\end{array}$ & $\begin{array}{c}100.0 \\
(88.7-100)\end{array}$ & 75.0 & 100.0 & - & ELISA IgM \\
\hline \multirow[t]{6}{*}{$\begin{array}{l}\text { Panbio } \\
\text { Dengue Duo }\end{array}$} & $\begin{array}{l}\text { Blacksell et } \\
\text { al. } 29 \text { (2006) }\end{array}$ & Thailand & CC & $491(326)$ & $\begin{array}{c}65.3 \\
(59.9-70.5)\end{array}$ & $\begin{array}{c}97.6 \\
(93.9-99.3)\end{array}$ & $\begin{array}{c}98.2 \\
(95.4-99.5)\end{array}$ & $\begin{array}{c}58.8 \\
(52.7-64.7)\end{array}$ & - & $\begin{array}{c}\text { RT-PCR } \\
\text { ELISA IgM/IgG }\end{array}$ \\
\hline & $\begin{array}{c}\text { Cohen et al. } 52 \\
\text { (2007) }\end{array}$ & & CS (acute) & 723 (132) & $\begin{array}{c}19.0 \\
(14.2-24.9)\end{array}$ & $\begin{array}{c}96.0 \\
(94.0-97.4)\end{array}$ & $\begin{array}{c}64.4 \\
(52.3-75.0)\end{array}$ & $\begin{array}{c}75.6 \\
(74.3-76.9)\end{array}$ & - & $\begin{array}{l}\text { ELISA IgM/ } \\
\text { IgG-HI }\end{array}$ \\
\hline & & & Conval. & & $\begin{array}{c}59.0 \\
(52.1-65.6)\end{array}$ & $\begin{array}{c}95.0 \\
(92.8-96.6)\end{array}$ & $\begin{array}{c}81.9 \\
(75.5-87.0)\end{array}$ & $\begin{array}{c}85.8 \\
(83.7-87.8)\end{array}$ & - & \\
\hline & $\begin{array}{l}\text { Congpuong et } \\
\text { al. } 53 \text { (2008) }\end{array}$ & Thailand & CS & $175(100)$ & $\begin{array}{c}23.0 \\
(15.8-32.2)\end{array}$ & $\begin{array}{c}100.0 \\
(95.1-100.0)\end{array}$ & 100.0 & 55.0 & $\begin{array}{l}1(37) \\
2(27) \\
3(69) \\
4(12)\end{array}$ & $\begin{array}{l}\text { Real time PCR } \\
\text { ELISA NS1/ } \\
\text { IgM/IgG }\end{array}$ \\
\hline & $\begin{array}{l}\text { Martínez-Vega } \\
\text { et al. } 54 \text { (2009) }\end{array}$ & Colombia & CS (acute) & $100(65)$ & $\begin{array}{c}52.2 \\
(40.3-64.2)\end{array}$ & $\begin{array}{c}84.8 \\
(72.6-97.1)\end{array}$ & $\begin{array}{c}87.5 \\
(77.3-97.7)\end{array}$ & $\begin{array}{c}46.7 \\
(34.0-59.3)\end{array}$ & $2(29)$ & $\begin{array}{l}\text { ELISA IgM } \\
\text { paired } \\
\text { samples }\end{array}$ \\
\hline & & & Conval. & & $\begin{array}{c}76.1 \\
(65.9-86.3)\end{array}$ & $\begin{array}{c}75.8 \\
(61.1-90.4)\end{array}$ & $\begin{array}{c}86.4 \\
(77.7-95.2)\end{array}$ & $\begin{array}{c}61.0 \\
(46.0-75.9)\end{array}$ & $2(29)$ & $\begin{array}{l}\text { ELISA IgM } \\
\text { paired } \\
\text { samples }\end{array}$ \\
\hline
\end{tabular}

(continues) 
Table 1 (continued)

\begin{tabular}{|c|c|c|c|c|c|c|c|c|c|c|}
\hline ICT & Study (year) & Country & $\begin{array}{c}\text { Design } \\
\text { 1ary:2nd } \\
\text { infection }\end{array}$ & $\begin{array}{c}\mathbf{N} \\
\text { (dengue } \\
\text { cases) }\end{array}$ & $\begin{array}{c}\text { Sn \% } \\
(95 \% \mathrm{Cl})\end{array}$ & $\begin{array}{c}\text { Sp \% } \\
(95 \% \mathrm{CI})\end{array}$ & $\begin{array}{c}\text { PPV \% } \\
(95 \% \mathrm{Cl})\end{array}$ & $\begin{array}{l}\text { NPV \% } \\
(95 \% \mathrm{Cl})\end{array}$ & $\operatorname{DENV}(n)$ & $\begin{array}{l}\text { Reference } \\
\text { standard }\end{array}$ \\
\hline & $\begin{array}{l}\text { Naz et al. } 27 \\
\text { (2014) }\end{array}$ & Pakistan & CS & $184(142)$ & $\begin{array}{c}72.5 \\
(64.4-79.7)\end{array}$ & $\begin{array}{c}69.1 \\
(52.9-82.4)\end{array}$ & $\begin{array}{c}88.8 \\
(81.6-93.9)\end{array}$ & $\begin{array}{c}42.7 \\
(30.7-55.2)\end{array}$ & $2(18)$ & ELISA IgM/IgG \\
\hline $\begin{array}{l}\text { Alere dengue } \\
\text { duo }\end{array}$ & $\begin{array}{l}\text { Fry et al. } 34 \\
(2011)\end{array}$ & Malaysia & $\mathrm{CC}$ & $293(263)$ & $\begin{array}{c}72.5 \\
(67.5-77.0)\end{array}$ & $\begin{array}{c}96.7 \\
(83.3-99.4)\end{array}$ & $\begin{array}{c}99.5 \\
(97.5-99.9)\end{array}$ & $\begin{array}{c}28.7 \\
(24.6-33.3)\end{array}$ & $\begin{array}{l}1(101) \\
2(21) \\
3(23) \\
4(16)\end{array}$ & $\begin{array}{c}\text { RT-PCR } \\
\text { ELISA NS1/ } \\
\text { IgM/lgG }\end{array}$ \\
\hline Dengue Fever & $\begin{array}{l}\text { Blacksell et } \\
\text { al. } 29 \text { (2006) }\end{array}$ & Thailand & $\mathrm{CC}$ & 491 (326) & $\begin{array}{c}9.5 \\
(6.6-13.2)\end{array}$ & $\begin{array}{c}97.0 \\
(93.0-99.0)\end{array}$ & $\begin{array}{c}86.1 \\
(70.5-95.3)\end{array}$ & $\begin{array}{c}35.2 \\
(30.8-39.8)\end{array}$ & - & $\begin{array}{c}\text { RT-PCR } \\
\text { ELISA IgM/IgG }\end{array}$ \\
\hline $\begin{array}{l}\text { Dengue } \\
\text { check-WB }\end{array}$ & $\begin{array}{l}\text { Blacksell et } \\
\text { al. } 29 \text { (2006) }\end{array}$ & Thailand & & & $\begin{array}{c}6.4 \\
(4.0-9.7)\end{array}$ & $\begin{array}{c}99.4 \\
(96.9-99.9)\end{array}$ & $\begin{array}{c}95.5 \\
(77.2-99.9)\end{array}$ & $\begin{array}{c}35.0 \\
(30.7-39.5)\end{array}$ & & \\
\hline Core Dengue & $\begin{array}{l}\text { Blacksell et } \\
\text { al. } 29 \text { (2006) }\end{array}$ & Thailand & & & $\begin{array}{c}22.9 \\
(18.3-27.6)\end{array}$ & $\begin{array}{c}98.9 \\
(95.7-99.9)\end{array}$ & $\begin{array}{c}97.4 \\
(90.8-99.7)\end{array}$ & $\begin{array}{c}39.3 \\
(34.6-44.2)\end{array}$ & & \\
\hline $\begin{array}{l}\text { Diazyme } \\
\text { Combo }\end{array}$ & $\begin{array}{l}\text { Blacksell et } \\
\text { al. } 29 \text { (2006) }\end{array}$ & Thailand & & & $\begin{array}{c}17.8 \\
(13.8-22.4)\end{array}$ & $\begin{array}{c}98.2 \\
(94.7-99.4)\end{array}$ & $\begin{array}{c}95.1 \\
(86.3-99.0)\end{array}$ & $\begin{array}{c}37.7 \\
(33.1-42.4)\end{array}$ & & \\
\hline $\begin{array}{l}\text { Smartcheck } \\
\text { Globale Med }\end{array}$ & $\begin{array}{l}\text { Blacksell et } \\
\text { al. } 29 \text { (2006) }\end{array}$ & Thailand & & & $\begin{array}{c}62.9 \\
(57.4-68.1)\end{array}$ & $\begin{array}{c}69.1 \\
(61.4-76.0)\end{array}$ & $\begin{array}{c}80.1 \\
(74.7-84.8)\end{array}$ & $\begin{array}{c}48.5 \\
(42.0-55.1)\end{array}$ & & \\
\hline $\begin{array}{l}\text { Vscan } \\
\text { (Minerva) }\end{array}$ & $\begin{array}{l}\text { Blacksell et } \\
\text { al. } 29 \text { (2006) }\end{array}$ & Thailand & & & $\begin{array}{c}8.6 \\
(5.8-12.2)\end{array}$ & $\begin{array}{c}100.0 \\
(97.8-100.0)\end{array}$ & $\begin{array}{c}100.0 \\
(87.7-100.0)\end{array}$ & $\begin{array}{c}35.6 \\
(31.3-40.2)\end{array}$ & - & $\begin{array}{c}\text { RT-PCR } \\
\text { ELISA IgM/IgG }\end{array}$ \\
\hline Acon & $\begin{array}{c}\text { Yusuf et al. } 57 \\
\text { (2008) }\end{array}$ & - & CS & $50(22)$ & $\begin{array}{c}45.8 \\
(31.6-60.7)\end{array}$ & $\begin{array}{c}100.0 \\
(19.8-100.0)\end{array}$ & $\begin{array}{c}100.0 \\
(81.5-100.0)\end{array}$ & $\begin{array}{c}71.0 \\
(56.0-84.0)\end{array}$ & - & ELISA \\
\hline $\begin{array}{l}\text { Dengue IgM/ } \\
\text { lgG }\end{array}$ & $\begin{array}{c}\text { Aikat et al. } 48 \\
\text { (2011) }\end{array}$ & - & CS & $158(29)$ & $\begin{array}{c}96.4 \\
(85.2-99.4)\end{array}$ & $\begin{array}{c}98.4 \\
(94.5-99.6)\end{array}$ & $\begin{array}{c}93.1 \\
(77.6-97.7)\end{array}$ & $\begin{array}{c}99.2 \\
(96.4-99.8)\end{array}$ & $\begin{array}{c}1(1) \\
2(16) \\
3(47) \\
4(2)\end{array}$ & ELISA IgM \\
\hline \multicolumn{11}{|l|}{$\begin{array}{l}\text { IgM/IgG } \\
\text { (only IgM) }\end{array}$} \\
\hline \multirow[t]{2}{*}{ SD Bioline } & $\begin{array}{l}\text { Pun et al. } 56 \\
\text { (2012) }\end{array}$ & Nepal & CS & $\begin{array}{l}131(50) \\
\text { acute }\end{array}$ & $\begin{array}{c}70.0 \\
(55.5-81.5)\end{array}$ & $\begin{array}{c}76.5 \\
(56.2-80.8)\end{array}$ & $\begin{array}{c}64.8 \\
(51.5-76.1)\end{array}$ & $\begin{array}{c}80.5 \\
(71.0-87.0)\end{array}$ & - & ELISA IgM \\
\hline & $\begin{array}{l}\text { Nga et al. } 55 \\
(2007)\end{array}$ & Vietnam & CS & $200(162)$ & $\begin{array}{c}10.6 \\
(6.0-18.0)\end{array}$ & $\begin{array}{c}99.0 \\
(94.3-99.8)\end{array}$ & $\begin{array}{c}91.7 \\
(64.6-98.5)\end{array}$ & $\begin{array}{c}80.5 \\
(43.5-57.6)\end{array}$ & - & ELISA IgM/IgG \\
\hline \multirow[t]{6}{*}{$\begin{array}{l}\text { Panbio } \\
\text { dengue duo }\end{array}$} & $\begin{array}{c}\text { Berry et al. } 49 \\
\text { (1998) }\end{array}$ & India & CS & $43(31)$ & $\begin{array}{c}41.7 \\
(19.3-68.1)\end{array}$ & $\begin{array}{c}96.8 \\
(83.8-99.4)\end{array}$ & $\begin{array}{c}83.0 \\
(47.3-96.5)\end{array}$ & $\begin{array}{c}81.1 \\
(72.4-87.5)\end{array}$ & - & $\begin{array}{c}\text { ELISA NS1/ } \\
\text { IgM }\end{array}$ \\
\hline & $\begin{array}{l}\text { Nga et al. } 55 \\
\text { (2007) }\end{array}$ & Vietnam & CS Conval. & $200(162)$ & $\begin{array}{c}67.3 \\
(59.7-74.0)\end{array}$ & $\begin{array}{c}92.1 \\
(79.2-97.3)\end{array}$ & $\begin{array}{c}97.3 \\
(92.9-99.0)\end{array}$ & $\begin{array}{c}39.8 \\
(34.2-45.7)\end{array}$ & - & ELISA IgM/IgG \\
\hline & $\begin{array}{l}\text { Blacksell et } \\
\text { al. } 50 \text { (2011) }\end{array}$ & Sri-Lanka & CS & 259 (99) & $\begin{array}{c}70.7 \\
(60.7-79.4)\end{array}$ & $\begin{array}{c}80.0 \\
(73.0-85.9)\end{array}$ & $\begin{array}{c}68.6 \\
(58.7-77.5)\end{array}$ & $\begin{array}{c}81.5 \\
(74.6-87.3)\end{array}$ & $\begin{array}{c}1(1) \\
2(16) \\
3(47) \\
4(2)\end{array}$ & $\begin{array}{c}\text { MAC GAC } \\
\text { ELISA paired } \\
\text { samples }\end{array}$ \\
\hline & $\begin{array}{l}\text { Pan-ngum et } \\
\text { al. } 42 \text { (2013) }\end{array}$ & Sri-Lanka & CS & 549 (135) & $\begin{array}{c}50.0 \\
(38.9-61.1)\end{array}$ & $\begin{array}{c}89.5 \\
(86.3-92.1)\end{array}$ & $\begin{array}{c}46.2 \\
(35.6-56.9)\end{array}$ & $\begin{array}{c}90.8 \\
(87.8-93.3)\end{array}$ & - & ELISA IgM/IgG \\
\hline & $\begin{array}{c}\text { Naz et al. } 27 \\
(2014)\end{array}$ & Pakistan & CS & & $\begin{array}{c}63.4 \\
(54.9-71.3)\end{array}$ & $\begin{array}{c}76.2 \\
(60.5-88.0)\end{array}$ & $\begin{array}{c}90.0 \\
(82.4-95.1)\end{array}$ & $\begin{array}{c}38.1 \\
(27.7-49.3)\end{array}$ & & \\
\hline & $\begin{array}{l}\text { Garg et al. } 60 \\
\quad(2019)\end{array}$ & India & $\mathrm{CC}$ & $152(72)$ & $\begin{array}{c}61.1 \\
(48.8-72.3\end{array}$ & $\begin{array}{c}95.1 \\
(87.7-98.6)\end{array}$ & $\begin{array}{c}91.7 \\
(80.0-97.6)\end{array}$ & $\begin{array}{c}91.7 \\
(80.0-97.6)\end{array}$ & - & $\begin{array}{l}\text { RT-PCR ELISA } \\
\text { NS1 IgM/lgG }\end{array}$ \\
\hline $\begin{array}{l}\text { Merlin } \\
\text { dengue }\end{array}$ & $\begin{array}{l}\text { Blacksell et } \\
\text { al. } 50 \text { (2011) }\end{array}$ & Sri-Lanka & CS & 259 (99) & $\begin{array}{c}72.7 \\
(62.9-81.2)\end{array}$ & $\begin{array}{c}73.8 \\
(66.2-80.4)\end{array}$ & $\begin{array}{c}63.2 \\
(53.2-72.0)\end{array}$ & $\begin{array}{c}81.4 \\
(74.1-87.4)\end{array}$ & $\begin{array}{c}1(1) \\
2(16) \\
3(47) \\
4(2)\end{array}$ & $\begin{array}{c}\text { RT-PCR } \\
\text { ELISA IgM/IgG }\end{array}$ \\
\hline $\begin{array}{l}\text { Biosynex } \\
\text { immunoquick }\end{array}$ & & & & 259 (99) & $\begin{array}{c}79.8 \\
(70.5-87.2)\end{array}$ & $\begin{array}{c}46.3 \\
(38.3-54.3)\end{array}$ & $\begin{array}{c}49.9 \\
(40.1-55.8)\end{array}$ & $\begin{array}{c}78.7 \\
(69.1-86.5)\end{array}$ & & \\
\hline
\end{tabular}

(continues) 
Table 1 (continued)

\begin{tabular}{|c|c|c|c|c|c|c|c|c|c|c|}
\hline ICT & Study (year) & Country & $\begin{array}{l}\text { Design } \\
\text { 1ary:2nd } \\
\text { infection }\end{array}$ & $\begin{array}{c}\mathrm{N} \\
\text { (dengue } \\
\text { cases) }\end{array}$ & $\begin{array}{c}\text { Sn \% } \\
(95 \% \mathrm{Cl})\end{array}$ & $\begin{array}{c}\text { Sp \% } \\
(95 \% \mathrm{Cl})\end{array}$ & $\begin{array}{c}\text { PPV \% } \\
(95 \% \mathrm{Cl})\end{array}$ & $\begin{array}{l}\text { NPV \% } \\
(95 \% \mathrm{CI})\end{array}$ & $\operatorname{DENV}(n)$ & $\begin{array}{l}\text { Reference } \\
\text { standard }\end{array}$ \\
\hline Asan & $\begin{array}{l}\text { Lee et al. } 37 \\
\text { (2019) }\end{array}$ & & $\mathrm{CC}$ & $138(75)$ & $\begin{array}{c}41.3 \\
(29.0-54.4)\end{array}$ & $\begin{array}{c}100.0 \\
(95.2-100.0)\end{array}$ & $\begin{array}{c}100.0 \\
(85.2-100.0)\end{array}$ & $\begin{array}{c}66.9 \\
(62.2-71.4)\end{array}$ & - & $\begin{array}{c}\text { PCR-ELISA } \\
\text { NS1//gM/lgG }\end{array}$ \\
\hline $\begin{array}{l}\text { Boditech } \\
\text { Medichroma }\end{array}$ & & & & $138(75)$ & $\begin{array}{c}85.7 \\
(74.6-93.3)\end{array}$ & $\begin{array}{c}92.0 \\
(83.4-97.0)\end{array}$ & $\begin{array}{c}90.0 \\
(80.6-95.1)\end{array}$ & $\begin{array}{c}88.5 \\
(80.7-93.4)\end{array}$ & & \\
\hline \multicolumn{11}{|l|}{ NS1/IgM/IgG } \\
\hline $\begin{array}{l}\text { SD Bioline } \\
\text { Dengue Duo }\end{array}$ & $\begin{array}{l}\text { Osorio et al. } 40 \\
\text { (2010) }\end{array}$ & Colombia & CC & $310(218)$ & $\begin{array}{c}80.7 \\
(75.0-85.4)\end{array}$ & $\begin{array}{c}89.1 \\
(81.1-94.0)\end{array}$ & $\begin{array}{c}94.6 \\
(90.8-96.9)\end{array}$ & $\begin{array}{c}66.1 \\
(59.6-72.1)\end{array}$ & - & $\begin{array}{c}\text { Viral Isolation } \\
\text { RT-PCR } \\
\text { ELISA IgM }\end{array}$ \\
\hline & $\begin{array}{l}\text { Tricou et al. } 46 \\
\text { (2010) }\end{array}$ & Vietnam & $\begin{array}{l}\text { Cohort } \\
\text { (acute) }\end{array}$ & $292(245)$ & $\begin{array}{c}83.7 \\
(78.4-88.1)\end{array}$ & $\begin{array}{c}97.9 \\
(88.7-99.9)\end{array}$ & $\begin{array}{c}99.5 \\
(97.3-100)\end{array}$ & $\begin{array}{c}53.5 \\
(42.4-64.3)\end{array}$ & $\begin{array}{l}1(138) \\
2(91) \\
3(16)\end{array}$ & $\begin{array}{c}\text { RT-PCR ELISA } \\
\text { IgM/lgG }\end{array}$ \\
\hline & $\begin{array}{l}\text { Andries et } \\
\text { al. } 58 \text { (2012) }\end{array}$ & & $\begin{array}{c}\text { Blood } \\
\text { (hospital) }\end{array}$ & $157(58)$ & $\begin{array}{c}85.7 \\
(78.4-91.3)\end{array}$ & $\begin{array}{c}83.9 \\
(66.3-94.5)\end{array}$ & $\begin{array}{c}95.6 \\
(90.0-98.5)\end{array}$ & $\begin{array}{c}59.1 \\
(43.2-73.7)\end{array}$ & & $\begin{array}{c}\text { RT-PCR } \\
\text { Viral Isolation } \\
\text { IgM and HIA } \\
\text { paired }\end{array}$ \\
\hline & & & (laboratory) & $157(57)$ & $\begin{array}{c}94.4 \\
(88.9-97.7)\end{array}$ & $\begin{array}{c}90.0 \\
(73.5-97.9)\end{array}$ & $\begin{array}{c}97.5 \\
(93.0-99.5)\end{array}$ & $\begin{array}{c}77.1 \\
(59.9-89.6)\end{array}$ & & \\
\hline & $\begin{array}{c}\text { Sanchez- } \\
\text { Vargas et al. } 70 \\
\text { (2014) }\end{array}$ & Mexico & $\begin{array}{c}\text { CC } \\
1: 1.2\end{array}$ & $397(310)$ & $\begin{array}{c}90.7 \\
(87.2-94.0)\end{array}$ & $\begin{array}{c}89.7 \\
(82.7-96.6)\end{array}$ & $\begin{array}{c}96.9 \\
(94.7-99.1)\end{array}$ & $\begin{array}{c}72.9 \\
(64.0-81.8)\end{array}$ & - & $\begin{array}{l}\text { ELISA NS1/ } \\
\text { IgM/lgG }\end{array}$ \\
\hline & $\begin{array}{c}\text { Gan et al. } 59 \\
\text { (2014) }\end{array}$ & Singapore & $\begin{array}{c}\text { CS } \\
1: 1.1\end{array}$ & 197 (147) & $\begin{array}{c}93.9 \\
(83.9-97.1)\end{array}$ & $\begin{array}{c}92.0 \\
(82.8-93.2)\end{array}$ & $\begin{array}{c}97.2 \\
(75.4-90.0)\end{array}$ & $\begin{array}{c}83.2 \\
(90.6-98.1)\end{array}$ & $\begin{array}{c}1(22) \\
2(89) \\
3(1)\end{array}$ & $\begin{array}{c}\text { RT-PCR } \\
\text { ELISA IgM }\end{array}$ \\
\hline & $\begin{array}{l}\text { Carter et al. } 79 \\
\text { (2015) }\end{array}$ & Cambodia & $\begin{array}{c}\mathrm{CS}<16 \\
\text { years }\end{array}$ & $337(71)$ & $\begin{array}{c}57.8 \\
(45.4-69.4)\end{array}$ & $\begin{array}{c}85.3 \\
(80.3-89.5)\end{array}$ & $\begin{array}{c}52.6 \\
(40.9-64.0)\end{array}$ & $\begin{array}{c}87.8 \\
(83.0-91.0)\end{array}$ & - & ELISA NS1 IgM \\
\hline & $\begin{array}{l}\text { Pal et al. } 69 \\
\text { (2015) }\end{array}$ & $\begin{array}{c}\text { Peru/ } \\
\text { Venezuela/ } \\
\text { Cambodia/ } \\
\text { Thailand/ } \\
\text { USA }\end{array}$ & $\begin{array}{c}\text { Cohort } \\
\text { 1:5 } \\
\text { (4-14 days) }\end{array}$ & $\begin{array}{l}1,108 \\
(377)\end{array}$ & $\begin{array}{c}87.3 \\
(84.1-90.2)\end{array}$ & $\begin{array}{c}86.8 \\
(83.9-89.3)\end{array}$ & $\begin{array}{c}77.4 \\
(73.9-80.6)\end{array}$ & $\begin{array}{c}93.0 \\
(91.0-94.5)\end{array}$ & $\begin{array}{l}1(88) \\
2(103) \\
3(24) \\
4(32)\end{array}$ & $\begin{array}{c}\text { PCR/Viral } \\
\text { isolation } \\
\text { In-house IgM/ } \\
\text { IgG PRNT }\end{array}$ \\
\hline & $\begin{array}{c}\text { Vickers et al. } 77 \\
\text { (2015) }\end{array}$ & Jamaica & $\begin{array}{l}\text { CC } \\
1: 3\end{array}$ & 339 (309) & $\begin{array}{c}97.5 \\
(92.9-99.2)\end{array}$ & $\begin{array}{c}100.0 \\
(86.3-100.0)\end{array}$ & $\begin{array}{c}100.0 \\
(97.9-100.0)\end{array}$ & $\begin{array}{c}93.6 \\
(79.3-98.2)\end{array}$ & $\mathrm{NI}$ & $\begin{array}{l}\text { ELISA NS1 } \\
\text { IGM }\end{array}$ \\
\hline & $\begin{array}{c}\text { Jusoh \& } \\
\text { Shueb } 36 \\
\text { (2017) }\end{array}$ & Malaysa & $\mathrm{CC}$ & $86(36)$ & $\begin{array}{c}88.9 \\
(75.8-96.6)\end{array}$ & $\begin{array}{c}100.0 \\
(92.9-100.0)\end{array}$ & - & - & $\begin{array}{c}1(14) \\
2(8) \\
3(2) \\
4(1) \\
1 \& 2(1)\end{array}$ & $\begin{array}{l}\text { ELISA NS1 } \\
\text { RT-PCR/viral } \\
\text { isolation }\end{array}$ \\
\hline & $\begin{array}{l}\text { Lee et al. }{ }^{37} \\
\quad(2019)\end{array}$ & & CC & $138(75)$ & $\begin{array}{c}82.7 \\
(72.2-90.4)\end{array}$ & $\begin{array}{c}100.0 \\
(94.3-100.0)\end{array}$ & $\begin{array}{c}100.0 \\
(93.9-100.0)\end{array}$ & $\begin{array}{c}82.9 \\
(74.7-88.8)\end{array}$ & - & $\begin{array}{c}\text { PCR-ELISA } \\
\text { NS1/lgM/lgG }\end{array}$ \\
\hline & (at least one) & & CC & $138(75)$ & $\begin{array}{c}83.7 \\
(78.4-88.1)\end{array}$ & $\begin{array}{c}97.9 \\
(88.7-99.9)\end{array}$ & $\begin{array}{c}99.5 \\
(97.3-100.0)\end{array}$ & $\begin{array}{c}53.5 \\
(42.4-64.3)\end{array}$ & - & $\begin{array}{c}\text { PCR-ELISA } \\
\text { NS1/lgM/lgG }\end{array}$ \\
\hline $\begin{array}{l}\text { ProDetect } \\
\text { Dengue Duo } \\
\text { (Mediven) }\end{array}$ & $\begin{array}{c}\text { Jusoh \& } \\
\text { Shueb } 36 \\
(2017)\end{array}$ & Malaysa & CC & $86(36)$ & $\begin{array}{c}94.4 \\
(81.9-98.5)\end{array}$ & $\begin{array}{c}96.0 \\
(86.5-98.9)\end{array}$ & $\begin{array}{c}94.4 \\
(83.3-98.3)\end{array}$ & $\begin{array}{c}96.0 \\
(87.7-98.8)\end{array}$ & $\begin{array}{c}1(14) \\
2(8) \\
3(2) \\
4(1) \\
1 \& 2(1)\end{array}$ & $\begin{array}{l}\text { ELISA NS1 } \\
\text { RT-PCR/viral } \\
\text { isolation }\end{array}$ \\
\hline
\end{tabular}

(continues) 
Table 1 (continued)

\begin{tabular}{|c|c|c|c|c|c|c|c|c|c|c|}
\hline ICT & Study (year) & Country & $\begin{array}{l}\text { Design } \\
\text { 1ary:2nd } \\
\text { infection }\end{array}$ & $\begin{array}{c}\mathbf{N} \\
\text { (dengue } \\
\text { cases) }\end{array}$ & $\begin{array}{c}\text { Sn \% } \\
(95 \% \mathrm{Cl})\end{array}$ & $\begin{array}{c}\text { Sp \% } \\
(95 \% \mathrm{Cl})\end{array}$ & $\begin{array}{c}\text { PPV \% } \\
(95 \% \mathrm{Cl})\end{array}$ & $\begin{array}{l}\text { NPV \% } \\
(95 \% \mathrm{Cl})\end{array}$ & $\operatorname{DENV}(\mathrm{n})$ & $\begin{array}{l}\text { Reference } \\
\text { standard }\end{array}$ \\
\hline $\begin{array}{l}\text { OneStep } \\
\text { NS1 RapiDIP } \\
\text { Instatest- } \\
\text { Rapicard IgM/ } \\
\text { IgG }\end{array}$ & $\begin{array}{c}\text { Vickers et al. } 76 \\
\text { (2017) } \\
\text { (fever } 4 \text { days) }\end{array}$ & Jamaica & $\begin{array}{c}\text { CC } \\
1: 1.1\end{array}$ & 339 (174) & $\begin{array}{c}99.5 \\
(97.1-99.9)\end{array}$ & $\begin{array}{c}100.0 \\
(87.5-100.0)\end{array}$ & $\begin{array}{c}100.0 \\
(98.0-100.0)\end{array}$ & $\begin{array}{c}96.4 \\
(82.3-99.4)\end{array}$ & & ELISA NS1 IgN \\
\hline Asan & $\begin{array}{l}\text { Lee et al. } 37 \\
\text { (2019) }\end{array}$ & & CC & $138(75)$ & $\begin{array}{c}77.3 \\
(66.3-86.2)\end{array}$ & $\begin{array}{c}98.4 \\
(91.5-99.9)\end{array}$ & $\begin{array}{c}98.3 \\
(89.2-99.8)\end{array}$ & $\begin{array}{c}78.5 \\
(70.6-84.7)\end{array}$ & - & $\begin{array}{c}\text { PCR-ELISA } \\
\text { NS1//gM/lgG }\end{array}$ \\
\hline \multicolumn{11}{|l|}{$\begin{array}{l}\text { NS1/IgM/IgG } \\
\text { (only NS1) }\end{array}$} \\
\hline $\begin{array}{l}\text { SD Bioline } \\
\text { Dengue Duo }\end{array}$ & $\begin{array}{l}\text { Osorio et al. } 40 \\
\text { (2010) }\end{array}$ & Colombia & CC & $310(218)$ & $\begin{array}{c}51.0 \\
(44.1-57.7)\end{array}$ & $\begin{array}{c}96.7 \\
(90.8-99.3)\end{array}$ & $\begin{array}{c}97.4 \\
(92.5-99.5)\end{array}$ & $\begin{array}{c}45.4 \\
(38.3-52.7)\end{array}$ & $\begin{array}{l}1(13) \\
2(17) \\
3(7) \\
4(5)\end{array}$ & $\begin{array}{c}\text { Viral isolation } \\
\text { RT-PCR } \\
\text { ELISA IgM }\end{array}$ \\
\hline & $\begin{array}{c}\text { Tricou et al. } 46 \\
\text { (2010) }\end{array}$ & Vietnam & Cohort & $292(245)$ & $\begin{array}{c}62.4 \\
(56.1-68.5)\end{array}$ & $\begin{array}{c}100.0 \\
(93.8-100.0)\end{array}$ & $\begin{array}{c}100.0 \\
(98.1-100.0)\end{array}$ & $\begin{array}{c}33.8 \\
(26.0-42.3)\end{array}$ & $\begin{array}{l}1(138) \\
2(91) \\
3(16)\end{array}$ & $\begin{array}{c}\text { ELISA IgM/lgG } \\
\text { RT-PCR }\end{array}$ \\
\hline & $\begin{array}{l}\text { Blacksell et } \\
\text { al. } 50 \text { (2011) }\end{array}$ & Sri Lanka & CC & 259 (99) & 48.5 & 99.4 & 98.0 & 75.7 & $\begin{array}{c}1(1) \\
2(16) \\
3(47) \\
4(2)\end{array}$ & $\begin{array}{c}\text { RT-PCR ELISA } \\
\text { IgM/IgG }\end{array}$ \\
\hline & $\begin{array}{l}\text { Sandoval et } \\
\text { al. } 71 \text { (2011) }\end{array}$ & Cuba & CS & $161(71)$ & $\begin{array}{c}57.8 \\
(45.6-69.9)\end{array}$ & $\begin{array}{c}98.9 \\
(96.2-100.0)\end{array}$ & $\begin{array}{c}97.6 \\
(86.8-99.4)\end{array}$ & $\begin{array}{c}74.8 \\
(66.2-81.6)\end{array}$ & $\begin{array}{c}1(53) \\
2(21) \\
3(1)\end{array}$ & $\begin{array}{l}\text { ELISA NS1/ } \\
\text { IgM/lgG }\end{array}$ \\
\hline & $\begin{array}{l}\text { Tontulawat et } \\
\text { al. } 75 \text { (2011) }\end{array}$ & Thailand & CS & $237(126)$ & $\begin{array}{c}70.3 \\
(61.2-78.0)\end{array}$ & $\begin{array}{c}73.0 \\
(64.7-80.0)\end{array}$ & $\begin{array}{c}69.6 \\
(62.7-75.8)\end{array}$ & $\begin{array}{c}73.6 \\
(67.3-79.1)\end{array}$ & - & $\begin{array}{c}\text { PCR semi- } \\
\text { nested ELISA } \\
\text { IgM }\end{array}$ \\
\hline & $\begin{array}{l}\text { Andries et } \\
\text { al. } 58 \text { (2012) }\end{array}$ & Cambodia & CS & $\begin{array}{l}126(31) \\
\text { (blood/ } \\
\text { hospital) }\end{array}$ & $\begin{array}{c}44.4 \\
(35.6-53.6)\end{array}$ & $\begin{array}{c}96.8 \\
(83.3-99.9)\end{array}$ & $\begin{array}{c}98.2 \\
(90.6-100.0)\end{array}$ & $\begin{array}{c}30.0 \\
(21.2-40.0)\end{array}$ & - & $\begin{array}{c}\text { RT-PCR } \\
\text { Viral isolation } \\
\text { ELISA IgM }\end{array}$ \\
\hline & & & & $\begin{array}{l}\text { (blood/ } \\
\text { labo- } \\
\text { ratory) }\end{array}$ & $\begin{array}{c}45.2 \\
(36.4-54.3)\end{array}$ & $\begin{array}{c}96.6 \\
(83.3-99.9)\end{array}$ & $\begin{array}{c}98.3 \\
(92.0-99.7)\end{array}$ & $\begin{array}{c}30.3 \\
(26.7-34.2)\end{array}$ & & \\
\hline & $\begin{array}{l}\text { Parham et } \\
\text { al. } 67 \text { (2013) }\end{array}$ & Honduras & CS & $61(48)$ & $\begin{array}{c}87.5 \\
(75.3-94.1)\end{array}$ & $\begin{array}{c}15.4 \\
(4.33-42.2)\end{array}$ & $\begin{array}{c}79.2 \\
(74.3-83.4)\end{array}$ & $\begin{array}{c}25.0 \\
(7.8-56.8)\end{array}$ & - & RT-PCR \\
\hline & $\begin{array}{c}\text { Gan et al. } 59 \\
(2014)\end{array}$ & Singapore & CS & $197(147)$ & $\begin{array}{c}81.6 \\
(74.6-87.1)\end{array}$ & $\begin{array}{c}98.0 \\
(89.5-99.7)\end{array}$ & $\begin{array}{c}99.2 \\
(99.5-99.9)\end{array}$ & $\begin{array}{c}64.5 \\
(53.3-74.3)\end{array}$ & $\begin{array}{c}1(22) \\
2(89) \\
3(1)\end{array}$ & $\begin{array}{l}\text { RT-PCR ELISA } \\
\text { NS1 /IgM/IgG }\end{array}$ \\
\hline & $\begin{array}{c}\text { Sanchez- } \\
\text { Vargas et al. } 70 \\
\text { (2014) }\end{array}$ & Mexico & $\begin{array}{c}\text { CC } \\
139: 171\end{array}$ & 397 (310) & $\begin{array}{c}87.5 \\
(81.6-93.43)\end{array}$ & $\begin{array}{c}94.6 \\
(91.7-97.6)\end{array}$ & $\begin{array}{c}89.5 \\
(83.9-95.1)\end{array}$ & $\begin{array}{c}93.6 \\
(90.4-96.7)\end{array}$ & - & $\begin{array}{l}\text { ELISA NS1/ } \\
\text { IgM/lgG }\end{array}$ \\
\hline & $\begin{array}{l}\text { Krishnanan- } \\
\text { thasivam et } \\
\text { al. } 65 \text { (2015) }\end{array}$ & Sri Lanka & CC & $143(27)$ & $\begin{array}{c}57.0 \\
(47.1-65.7)\end{array}$ & $\begin{array}{c}86.7 \\
(59.5-95.9)\end{array}$ & $\begin{array}{c}97.3 \\
(90.7-99.6)\end{array}$ & $\begin{array}{c}19.1 \\
(10.6-30.5)\end{array}$ & & $\begin{array}{l}\text { RT-PCR ELISA } \\
\text { IgM IgG }\end{array}$ \\
\hline
\end{tabular}

(continues) 
Table 1 (continued)

\begin{tabular}{|c|c|c|c|c|c|c|c|c|c|c|}
\hline ICT & Study (year) & Country & $\begin{array}{c}\text { Design } \\
\text { 1ary:2nd }^{\text {na }} \\
\text { infection }\end{array}$ & $\begin{array}{c}\mathbf{N} \\
\text { (dengue } \\
\text { cases) }\end{array}$ & $\begin{array}{c}\text { Sn \% } \\
(95 \% \mathrm{Cl})\end{array}$ & $\begin{array}{c}\mathrm{Sp} \% \\
(95 \% \mathrm{Cl})\end{array}$ & $\begin{array}{l}\text { PPV \% } \\
(95 \% \mathrm{Cl})\end{array}$ & $\begin{array}{l}\text { NPV \% } \\
(95 \% \mathrm{Cl})\end{array}$ & $\operatorname{DENV}(n)$ & $\begin{array}{l}\text { Reference } \\
\text { standard }\end{array}$ \\
\hline & $\begin{array}{l}\text { Hunsperger et } \\
\text { al. } 62 \text { (2016) }\end{array}$ & & CC & $\begin{array}{c}1,678 \\
(1,116)\end{array}$ & $\begin{array}{c}65.9 \\
(62.2,69.4)\end{array}$ & $\begin{array}{c}80.9 \\
(77.8,83.8)\end{array}$ & - & - & $\begin{array}{c}1(31) \\
2(188) \\
3(89) \\
4(430)\end{array}$ & RT-PCR \\
\hline & & Angola & & $46(43)$ & $\begin{array}{c}92.9 \\
(76.5-99.1)\end{array}$ & $\begin{array}{c}22.0 \\
(6.4-47.6)\end{array}$ & - & - & $1(29)$ & \\
\hline & & $\begin{array}{l}\text { Marshall } \\
\text { Island }\end{array}$ & & $796(430)$ & $\begin{array}{c}66.8 \\
(61.9-71.3)\end{array}$ & $\begin{array}{c}79.9 \\
(74.3-84.7)\end{array}$ & - & - & $4(430)$ & \\
\hline & & Fiji & & $302(148)$ & $\begin{array}{c}84.4 \\
(75.3-91.2)\end{array}$ & $\begin{array}{c}78.2 \\
(71.8-83.7)\end{array}$ & - & - & $3(89)$ & \\
\hline & & Yap Island & & $534(332)$ & $\begin{array}{c}49.7 \\
(42.0-57.4)\end{array}$ & $\begin{array}{c}89.0 \\
(84.2-92.7)\end{array}$ & - & - & $2(175)$ & \\
\hline & $\begin{array}{c}\text { Garg et al. } 60 \\
\text { (2019) }\end{array}$ & India & CC & $152(72)$ & $\begin{array}{c}100.0 \\
(94.6-100.0 .)\end{array}$ & $\begin{array}{c}100.0 \\
(95.5-100.0)\end{array}$ & $\begin{array}{c}100.0 \\
(94.6-100.0)\end{array}$ & $\begin{array}{c}100.0 \\
(95.5-100.0)\end{array}$ & - & \\
\hline & $\begin{array}{l}\text { Shih et al. } 72 \\
\quad(2016)\end{array}$ & Taiwan & $\begin{array}{c}\text { CS (acute) } \\
\text { Median } 17 \\
\text { years }\end{array}$ & $\begin{array}{c}1,607 \\
(1,295)\end{array}$ & $\begin{array}{c}94.9 \\
(92.1-96.7)\end{array}$ & $\begin{array}{c}70.9 \\
(63.0-77.8)\end{array}$ & $\begin{array}{c}89.5 \\
(86.9-91.7)\end{array}$ & $\begin{array}{c}84.0 \\
(77.1-89.2)\end{array}$ & - & \\
\hline & $\begin{array}{l}\text { Huits et al. } 61 \\
\text { (2017) }\end{array}$ & Belgium & Cohort 4:1 & $308(52)$ & $\begin{array}{c}82.7 \\
(74.4-93.0)\end{array}$ & $\begin{array}{c}99.6 \\
(98.8-100)\end{array}$ & $\begin{array}{c}97.7 \\
(89.6-99.5)\end{array}$ & $\begin{array}{c}96.6 \\
(94.1-98.1)\end{array}$ & - & \\
\hline & $\begin{array}{l}\text { Simonnet et } \\
\text { al. } 74 \text { (2017) }\end{array}$ & $\begin{array}{l}\text { French } \\
\text { Guiana }\end{array}$ & $\begin{array}{l}\text { Cohort } \\
\text { (acute) }\end{array}$ & $\begin{array}{l}3,347 \\
(475)\end{array}$ & $\begin{array}{c}87.6 \\
(84.3-90.2)\end{array}$ & $\begin{array}{c}98.1 \\
(97.5-98.5)\end{array}$ & $\begin{array}{c}88.3 \\
(85.3-90.8)\end{array}$ & $\begin{array}{c}97.9 \\
(97.4-98.4)\end{array}$ & - & \\
\hline & $\begin{array}{l}\text { Liu et al. } 68 \\
\text { (2018) }\end{array}$ & $\begin{array}{l}\text { Solomon } \\
\text { Island }\end{array}$ & $\begin{array}{c}\text { CS } \\
216: 14\end{array}$ & $412(242)$ & $\begin{array}{c}90.9 \\
(87.0-94.0)\end{array}$ & $\begin{array}{c}100.0 \\
(98.0-100.0)\end{array}$ & $\begin{array}{c}100.0 \\
(98.0-100.0)\end{array}$ & $\begin{array}{c}88.5 \\
(83.0-93.0)\end{array}$ & $3(242)$ & \\
\hline & $\begin{array}{l}\text { Kikuti et al. } 64 \\
\text { (2019) }\end{array}$ & Brazil & $\begin{array}{c}\text { CC } \\
45: 199\end{array}$ & $500(246)$ & $\begin{array}{c}38.6 \\
(32.5-45.0)\end{array}$ & $\begin{array}{c}98.2 \\
(93.5-99.8)\end{array}$ & $\begin{array}{c}97.9 \\
(93.2-99.4)\end{array}$ & $\begin{array}{c}58.8 \\
(56.2-61.2)\end{array}$ & $\begin{array}{c}1(18) \\
2(113) \\
4(49)\end{array}$ & \\
\hline & $\begin{array}{l}\text { Lee et al. } 37 \\
\text { (2019) }\end{array}$ & Korea & $\mathrm{CC}$ & $138(75)$ & $\begin{array}{c}49.2 \\
(36.4-62.1)\end{array}$ & $\begin{array}{c}98.7 \\
(92.8-99.9)\end{array}$ & $\begin{array}{c}96.9 \\
(81.3-99.5)\end{array}$ & $\begin{array}{c}69.8 \\
(64.4-74.7)\end{array}$ & - & $\begin{array}{c}\text { PCR-ELISA } \\
\text { NS1//gM/lgG }\end{array}$ \\
\hline & & & CC & $138(75)$ & $\begin{array}{c}57.1 \\
(28.9-82.3)\end{array}$ & $\begin{array}{c}100.0 \\
(97.1-100.0)\end{array}$ & $\begin{array}{c}100.0 \\
(63.6-100.0)\end{array}$ & $\begin{array}{c}95.4 \\
(91.9-97.4)\end{array}$ & - & ELISA IgM \\
\hline & $\begin{array}{c}\text { Jang et al. } 63 \\
\text { (2019) }\end{array}$ & Myanmar & $\begin{array}{l}\text { CC } \\
1: 4\end{array}$ & 172 (109) & $\begin{array}{c}48.6 \\
(38.9-58.4)\end{array}$ & $\begin{array}{c}100.0 \\
(94.3-100.0)\end{array}$ & 100.0 & 52.9 & & $\begin{array}{c}\text { qRT-PCR ELISA } \\
\text { IgM/lgG }\end{array}$ \\
\hline CTK Biotech & $\begin{array}{l}\text { Liu et al. } 68 \\
\text { (2018) }\end{array}$ & $\begin{array}{l}\text { Solomon } \\
\text { Island }\end{array}$ & $\begin{array}{c}\text { CS } \\
216: 14\end{array}$ & $412(242)$ & $\begin{array}{c}92.6 \\
(88.6-95.2)\end{array}$ & $\begin{array}{c}78.8 \\
(72.1-84.3)\end{array}$ & $\begin{array}{c}86.2 \\
(82.3-89.3)\end{array}$ & $\begin{array}{c}88.2 \\
(82.7-92.1)\end{array}$ & $3(242)$ & $\begin{array}{l}\text { Real-time } \\
\text { qRT-PCR }\end{array}$ \\
\hline Dengucheck & $\begin{array}{c}\text { Garg et al. } 60 \\
\text { (2019) }\end{array}$ & India & $\mathrm{CC}$ & $152(72)$ & $\begin{array}{c}100.0 \\
(94.6-100.0)\end{array}$ & $\begin{array}{c}100.0 \\
(95.5-100.0)\end{array}$ & $\begin{array}{c}100.0 \\
(94.6-100.0)\end{array}$ & $\begin{array}{c}100.0 \\
(95.5-100.0)\end{array}$ & - & $\begin{array}{l}\text { RT-PCR ELISA } \\
\text { NS1 IgM/lgG }\end{array}$ \\
\hline \multirow[t]{2}{*}{ Dengue day 1} & & & & & $\begin{array}{c}94.4 \\
(86.3-98.4)\end{array}$ & $\begin{array}{c}100.0 \\
(98.5-100.0)\end{array}$ & 100.0 & $\begin{array}{c}95.2 \\
(88.2-98.6)\end{array}$ & & \\
\hline & $\begin{array}{c}\text { Shukla et al. } 73 \\
\text { (2017) }\end{array}$ & India & CS & 249 (128) & $\begin{array}{c}93.6 \\
(87.8-96.7)\end{array}$ & $\begin{array}{c}91.1 \\
(84.8-94.9)\end{array}$ & 91.4 & 93.4 & $\begin{array}{l}1(79) \\
2(85) \\
3(85)\end{array}$ & RT-PCR \\
\hline Humasis & $\begin{array}{l}\text { Jang et al. } 63 \\
\qquad(2019)\end{array}$ & Myanmar & $\begin{array}{l}\text { CC } \\
1: 4\end{array}$ & $172(109)$ & $\begin{array}{c}63.3 \\
(53.5-72.3)\end{array}$ & $\begin{array}{c}100.0 \\
(94.3-100.0)\end{array}$ & 100.0 & 44.0 & & $\begin{array}{c}\text { qRT-PCR ELISA } \\
\operatorname{lgM} / \lg G\end{array}$ \\
\hline $\begin{array}{l}\text { Humasis NS1/ } \\
\text { IgM }\end{array}$ & $\begin{array}{c}\text { Kyaw et al. } 66 \\
\text { (2019) }\end{array}$ & Myanmar & $\begin{array}{l}\text { CS } \\
1: 1\end{array}$ & $202(140)$ & $\begin{array}{c}68.6 \\
(60.2-76.1)\end{array}$ & $\begin{array}{c}90.3 \\
(80.1-96.4)\end{array}$ & $\begin{array}{c}94.1 \\
(87.6-97.8)\end{array}$ & $\begin{array}{c}56.0 \\
(45.7-65.9)\end{array}$ & $\begin{array}{l}1(57) \\
2(7) \\
3(6) \\
4(10)\end{array}$ & $\begin{array}{c}\text { ELISA IgM/IgG } \\
\text { RT-PCR }\end{array}$ \\
\hline Careus & $\begin{array}{l}\text { Jang et al. } 63 \\
\text { (2019) }\end{array}$ & Myanmar & $\begin{array}{l}\text { CC } \\
1: 4\end{array}$ & $172(109)$ & $\begin{array}{c}79.8 \\
(71.1-86.9)\end{array}$ & $\begin{array}{c}100.0 \\
(94.3-100.0)\end{array}$ & 100.0 & 74.1 & & $\begin{array}{c}\text { qRT-PCR ELISA } \\
\text { IgM/lgG }\end{array}$ \\
\hline
\end{tabular}

(continues) 
Table 1 (continued)

\begin{tabular}{|c|c|c|c|c|c|c|c|c|c|c|}
\hline ICT & Study (year) & Country & $\begin{array}{c}\text { Design } \\
\text { 1ary:2nd } \\
\text { infection }\end{array}$ & $\begin{array}{c}\mathrm{N} \\
\text { (dengue } \\
\text { cases) }\end{array}$ & $\begin{array}{c}\text { Sn \% } \\
(95 \% \mathrm{Cl})\end{array}$ & $\begin{array}{c}\text { Sp \% } \\
(95 \% \mathrm{Cl})\end{array}$ & $\begin{array}{l}\text { PPV \% } \\
(95 \% \mathrm{CI})\end{array}$ & $\begin{array}{l}\text { NPV \% } \\
(95 \% \mathrm{CI})\end{array}$ & $\operatorname{DENV}(\mathrm{n})$ & $\begin{array}{l}\text { Reference } \\
\text { standard }\end{array}$ \\
\hline $\begin{array}{l}\text { CareUs NS1/ } \\
\text { IgM }\end{array}$ & $\begin{array}{l}\text { Kyaw et al. } 66 \\
\text { (2019) }\end{array}$ & Myanmar & $\begin{array}{l}\mathrm{CS} \\
1: 1\end{array}$ & $202(140)$ & $\begin{array}{c}72.1 \\
(63.9-79.4)\end{array}$ & $\begin{array}{c}87.1 \\
(76.1-94.3)\end{array}$ & $\begin{array}{c}92.7 \\
(86.0-96.8)\end{array}$ & $\begin{array}{c}58.1 \\
(47.4-68.2)\end{array}$ & $\begin{array}{l}1(57) \\
2(7) \\
3(6) \\
4(10)\end{array}$ & $\begin{array}{c}\text { ELISA IgM/IgG } \\
\text { RT-PCR }\end{array}$ \\
\hline $\begin{array}{l}\text { Wondfo NS1/ } \\
\text { IgM }\end{array}$ & $\begin{array}{c}\text { Kyaw et al. } 66 \\
\text { (2019) }\end{array}$ & Myanmar & $\begin{array}{l}\text { CS } \\
1: 1\end{array}$ & $202(140)$ & $\begin{array}{c}67.1 \\
(58.7-74.8)\end{array}$ & $\begin{array}{c}91.9 \\
(82.2-97.3)\end{array}$ & $\begin{array}{c}94.9 \\
(88.6-98.3)\end{array}$ & $\begin{array}{c}55.3 \\
(45.2-65.1)\end{array}$ & & \\
\hline \multirow[t]{5}{*}{$\begin{array}{l}\text { SD Bioline } \\
\text { duo }\end{array}$} & $\begin{array}{l}\text { Blacksell et al. } \\
50(2011)\end{array}$ & Sri Lanka & CS & 259 (99) & $\begin{array}{c}79.2 \\
(70.5-87.2)\end{array}$ & $\begin{array}{c}89.4 \\
(83.5-93.7)\end{array}$ & $\begin{array}{c}82.3 \\
(73.2-89.3)\end{array}$ & $\begin{array}{c}87.7 \\
(81.7-92.3)\end{array}$ & $\begin{array}{c}1(1) \\
2(16) \\
3(47) \\
4(2)\end{array}$ & $\begin{array}{c}\text { RT-PCR } \\
\text { ELISA IgM/IgG }\end{array}$ \\
\hline & $\begin{array}{c}\text { Parham et al. } \\
67 \text { (2013) }\end{array}$ & & CS & $61(48)$ & $\begin{array}{c}82.5 \\
(70.6-90.2)\end{array}$ & $\begin{array}{c}87.5 \\
(64.0-96.5)\end{array}$ & $\begin{array}{c}95.9 \\
(87.8-98.7)\end{array}$ & $\begin{array}{c}58.3 \\
(43.7-71.6)\end{array}$ & $\begin{array}{l}1(50) \\
2(50) \\
3(58)\end{array}$ & RT-PCR \\
\hline & $\begin{array}{c}\text { Sanchez- } \\
\text { Vargas et al. } 70 \\
\text { (2014) }\end{array}$ & Mexico & $\begin{array}{c}\text { CC } \\
1: 1.2\end{array}$ & $397(310)$ & $\begin{array}{c}60.5 \\
(53.4-67.6)\end{array}$ & $\begin{array}{c}94.1 \\
(90.6-97.6)\end{array}$ & $\begin{array}{c}90.8 \\
(85.4-96.1)\end{array}$ & $\begin{array}{c}71.2 \\
(65.5-76.8)\end{array}$ & - & $\begin{array}{l}\text { ELISA NS1/ } \\
\text { IgM/IgG }\end{array}$ \\
\hline & $\begin{array}{c}\text { Shih et al. } 72 \\
(2016)\end{array}$ & Taiwan & CS & $\begin{array}{c}1,607 \\
(1,295)\end{array}$ & $\begin{array}{c}10.0 \\
(7.3-13.5)\end{array}$ & $\begin{array}{c}66.0 \\
(57.8-73.3)\end{array}$ & - & - & - & RT-PCR \\
\hline & $\begin{array}{c}\text { Simonet et al. } \\
74 \text { (2017) }\end{array}$ & $\begin{array}{l}\text { French } \\
\text { Guiana }\end{array}$ & Cohort & $\begin{array}{l}3,347 \\
(475)\end{array}$ & $\begin{array}{c}44.8 \\
(39.9-50.0)\end{array}$ & $\begin{array}{c}98.3 \\
(97.8-98.7)\end{array}$ & $\begin{array}{c}75.9 \\
(70.2-80.9)\end{array}$ & $\begin{array}{c}93.7 \\
(93.1-94.2)\end{array}$ & - & Dx select IgM \\
\hline \multirow[t]{8}{*}{$\begin{array}{l}\text { SD Bioline } \\
\text { Dengue Duo }\end{array}$} & $\begin{array}{c}\text { Hunsperger et } \\
\text { al. } 62 \text { (2016) }\end{array}$ & Angola & CC & $46(14)$ & $\begin{array}{c}91.7 \\
(61.5-99.8)\end{array}$ & $\begin{array}{c}85.3 \\
(68.9-95.1)\end{array}$ & - & - & $1(29)$ & ELISA IgM \\
\hline & & $\begin{array}{l}\text { Marshall } \\
\text { Island }\end{array}$ & & 796 (53) & $\begin{array}{c}80.0 \\
(61.4-92.3)\end{array}$ & $\begin{array}{c}92.2 \\
(88.9-94.8)\end{array}$ & - & - & $4(430)$ & \\
\hline & & Fiji & & $302(38)$ & $\begin{array}{c}55.3 \\
(38.3-71.4)\end{array}$ & $\begin{array}{c}78.2 \\
(96.2-99.6)\end{array}$ & - & - & $3(89)$ & \\
\hline & & Yap Island & & $534(53)$ & $\begin{array}{c}56.6 \\
(42.3-70.2)\end{array}$ & $\begin{array}{c}93.1 \\
(91.4-95.9)\end{array}$ & - & - & $2(175)$ & \\
\hline & $\begin{array}{l}\text { Lee et al. } 37 \\
\text { (2019) }\end{array}$ & & $\mathrm{CC}$ & $138(75)$ & $\begin{array}{c}49.2 \\
(36.4-62.1)\end{array}$ & $\begin{array}{c}98.7 \\
(92.8-99.9)\end{array}$ & $\begin{array}{c}96.9 \\
(81.3-99.5)\end{array}$ & $\begin{array}{c}69.8 \\
(64.4-74.7)\end{array}$ & - & $\begin{array}{c}\text { PCR-ELISA } \\
\mathrm{NS} 1 / \operatorname{lgM} / \operatorname{lgG}\end{array}$ \\
\hline & $\begin{array}{l}\text { Kikuti et al. } 64 \\
\text { (2019) }\end{array}$ & Brazil & $\begin{array}{c}\text { CC } \\
1: 4.4 \\
\text { (acute) }\end{array}$ & $500(246)$ & $\begin{array}{c}13.8 \\
(9.8-18.8)\end{array}$ & $\begin{array}{c}96.3 \\
(90.8-99.0)\end{array}$ & $\begin{array}{c}89.5 \\
(76.5-95.7)\end{array}$ & $\begin{array}{c}32.9 \\
(31.5-34.3)\end{array}$ & $\begin{array}{c}1(18) \\
2(113) \\
4(49)\end{array}$ & $\begin{array}{c}\text { RT-PCR ELISA } \\
\text { NS1/lgM } \\
\text { paired/IgG }\end{array}$ \\
\hline & $\begin{array}{c}\text { Garg et al. } 60 \\
\text { (2019) }\end{array}$ & India & CC & $152(72)$ & $\begin{array}{c}44.5 \\
(32.7-56.6)\end{array}$ & $\begin{array}{c}100.0 \\
(97.5-100.0)\end{array}$ & 100.0 & $\begin{array}{c}66.7 \\
(57.4-75.1)\end{array}$ & - & $\begin{array}{l}\text { RT-PCR ELISA } \\
\text { NS1 IgM/lgG }\end{array}$ \\
\hline & $\begin{array}{l}\text { Jang et al. } 63 \\
\text { (2019) }\end{array}$ & Myanmar & $\begin{array}{l}\text { CC } \\
1: 4\end{array}$ & 172 (109) & $\begin{array}{c}60.6 \\
(50.7-69.8)\end{array}$ & $\begin{array}{c}100.0 \\
(94.3-100.0)\end{array}$ & 100.0 & 59.4 & & $\begin{array}{c}\text { qRT-PCR ELISA } \\
\text { IgM/lgG }\end{array}$ \\
\hline Dengucheck & $\begin{array}{l}\text { Garg et al. } 60 \\
\text { (2019) }\end{array}$ & India & $\mathrm{CC}$ & $152(72)$ & $\begin{array}{c}77.7 \\
(66.4-86.7)\end{array}$ & $\begin{array}{c}50.0 \\
(38.6-61.4)\end{array}$ & $\begin{array}{c}58.3 \\
(47.8-68.3)\end{array}$ & $\begin{array}{c}71.4 \\
(57.8-82.7)\end{array}$ & - & $\begin{array}{l}\text { RT-PCR ELISA } \\
\text { NS1 IgM/IgG }\end{array}$ \\
\hline Dengue day 1 & $\begin{array}{l}\text { Garg et al. } 60 \\
\text { (2019) }\end{array}$ & India & $\mathrm{CC}$ & $152(72)$ & $\begin{array}{c}27.8 \\
(17.8-39.6)\end{array}$ & $\begin{array}{c}65.0 \\
(53.5-75.3)\end{array}$ & $\begin{array}{c}41.6 \\
(27.6-56.8)\end{array}$ & $\begin{array}{c}50.0 \\
(40.0-60.0)\end{array}$ & - & $\begin{array}{l}\text { RT-PCR ELISA } \\
\text { NS1 IgM/IgG }\end{array}$ \\
\hline Humasis & $\begin{array}{l}\text { Jang et al. } 63 \\
\text { (2019) }\end{array}$ & Myanmar & $\begin{array}{l}\text { CC } \\
1: 4\end{array}$ & $172(109)$ & $\begin{array}{c}51.4 \\
(41.6-61.1)\end{array}$ & $\begin{array}{c}98.2 \\
(91.5-99.9)\end{array}$ & 98.2 & 53.9 & & $\begin{array}{c}\text { qRT-PCR ELISA } \\
\operatorname{lgM} / \operatorname{lgg}\end{array}$ \\
\hline CareUS & $\begin{array}{c}\text { Jang et al. } 63 \\
\text { (2019) }\end{array}$ & Myanmar & $\begin{array}{l}\text { CC } \\
1: 4\end{array}$ & 172 (109) & $\begin{array}{c}89.9 \\
(82.7-94.8)\end{array}$ & $\begin{array}{c}100.0 \\
(94.3-100.0)\end{array}$ & 100.0 & 85.1 & & $\begin{array}{c}\text { qRT-PCR ELISA } \\
\text { IgM/lgG }\end{array}$ \\
\hline
\end{tabular}

95\%Cl: 95\% confidence interval; CC: case-control study; Conval.: convalescent sample; CS: cross-sectional study; DENV: dengue virus; NPV: negative predictive value; PPV: positive predictive value; Sn: sensitivity; Sp: specificity; Read.: reading time. 


\section{Figure 2}

Quality assessment and risk of bias of the selected studies using the Quality Assessment of Diagnostic Accuracy Studies (QUADAS 2).

2a) Risk of bias

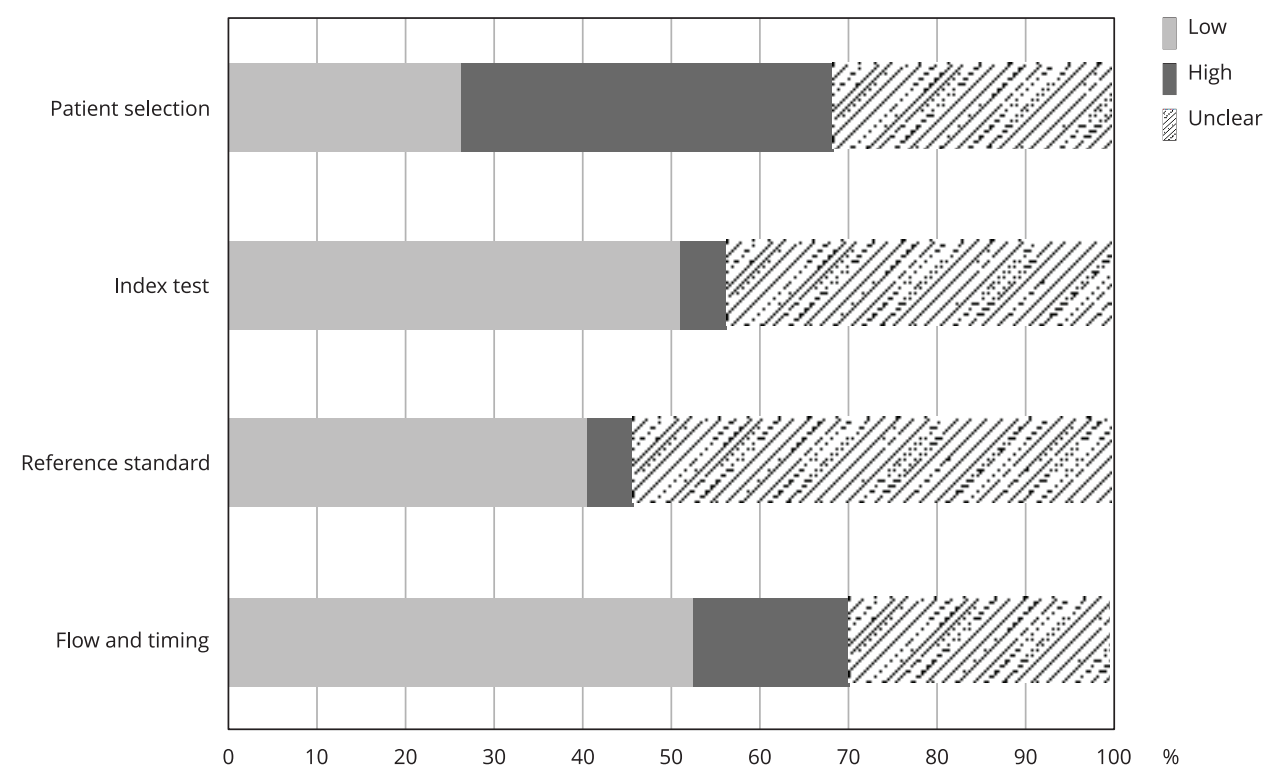

2b) Concerns regarding applicability

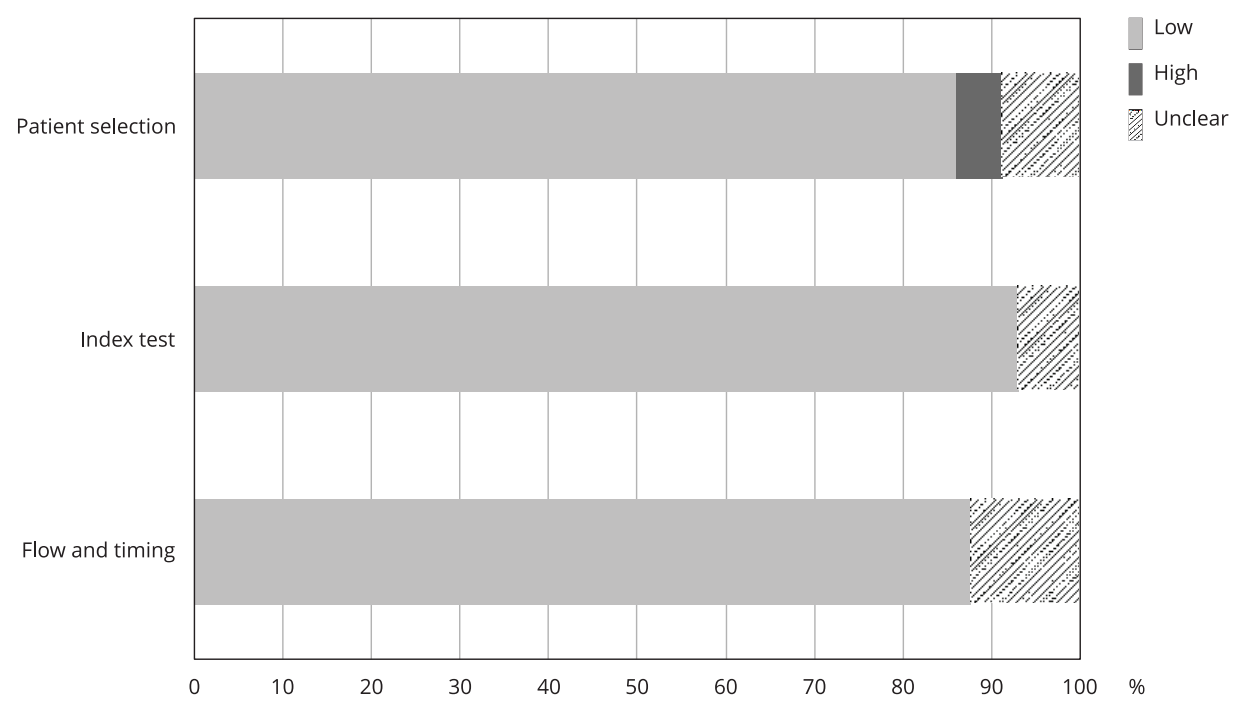




\section{Rapid immunochromatographic tests with IgA detection}

A total of 2,051 samples from patients with suspected dengue virus infection were analyzed (median 342, interquartile range [IQR]: 100-914) in the five studies selected for this part of the review 24,25,27,27,28. One of them showed results in acute and convalescent samples 24 . Pooled estimate of the IgA tests showed a sensitivity of $88 \%$ and specificity of $90 \%$ (Table 2). It was not possible to assess publication bias for these tests due to the small number of studies included in the analysis. The pooled estimate in the acute phase showed slightly higher sensitivity (92.8 vs. 88 ) and the same specificity (90\%) compared with the analysis which included convalescent samples. The performance of this test for screening was better than NS1 or IgM/IgG due to better sensitivity (Table 2), but lower than tests with three analytes.

Forest plots (Figure 3) showed similar results between studies, except for one case-control 26 which included mainly primary infections compared to secondary infections (5:1), despite high statistical heterogeneity $\left(I^{2}=93 \%\right)$. IgA ICT tests in scenarios with prevalence of $25 \%$ showed the positive post-test probability still moderately high (75\%) compared to conclusive $(90 \%$ and $96 \%)$ results in epidemic scenarios (Table 2). Besides that, the negative post-test probabilities were reasonable up to $12 \%$ and $18 \%$ even in outbreaks (Table 2).

Only one study 26 reported the serotypes tested (Table 1). This study assessed the performance according to serotype (DENV-1 and 2), showing heterogeneous sensitivities ( $\mathrm{S} n=52.4 \%$ in DENV-1 and $73.9 \%$ in DENV-2).

Three studies 24,26,27 included primary and secondary dengue infection cases without stratified analysis.

\section{Rapid immunochromatographic tests with NS1 detection}

Tests based exclusively on NS1 evaluated three brands up to 2014: Bio-Rad, Panbio, Alere/Bio_Easy.

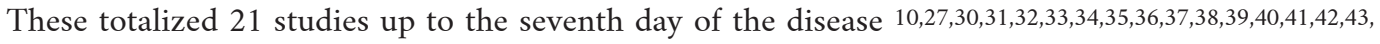
$44,45,46,47,50$, one of which 34 presented the results of two settings, one in Malaysia and the other in Vietnam. The tests were assessed in 6,618 samples from patients with suspected dengue (median 241). Of 21 studies, 18 reported the serotypes tested, totaling 852 samples of DENV-1, 582 DENV-2, 501 DENV-3, and 510 DENV-4 (Table 1), but did not show stratified performance analysis.

Table 2

Meta-analysis of the accuracy of rapid immunochromatographic tests (ICT) according to the analytes of the diagnostic method.

\begin{tabular}{|c|c|c|c|c|c|c|c|c|c|}
\hline $\begin{array}{l}\text { ICT } \\
\text { (samples) }\end{array}$ & $\begin{array}{c}\text { Sn \% } \\
(95 \% \mathrm{Cl})\end{array}$ & $\begin{array}{c}\mathrm{Sp} \% \\
(95 \% \mathrm{Cl})\end{array}$ & $\begin{array}{c}\text { LR+ } \\
(95 \% \mathrm{Cl})\end{array}$ & $\begin{array}{c}\text { LR- } \\
(95 \% \mathrm{Cl})\end{array}$ & $\begin{array}{c}\text { DOR } \\
(95 \% \mathrm{Cl})\end{array}$ & $\begin{array}{c}\mathrm{PP}+ \\
(25 \% ; 50 \% ; 75 \%)\end{array}$ & $\begin{array}{c}\text { PP- } \\
(25 \% ; 50 \% ; 75 \%)\end{array}$ & $\begin{array}{l}12(\%) \text { Sn } \\
(95 \% \mathrm{Cl})\end{array}$ & $\begin{array}{l}12(\%) \mathrm{Sp} \\
(95 \% \mathrm{Cl})\end{array}$ \\
\hline $\begin{array}{l}\text { IgA all } \\
(n=6)\end{array}$ & $\begin{array}{c}88.0 \\
(73.0-95.0)\end{array}$ & $\begin{array}{c}90.0 \\
(78.0-96.0)\end{array}$ & $\begin{array}{c}9.1 \\
(3.7-22.3)\end{array}$ & $\begin{array}{c}0.13 \\
(0.05-0.33)\end{array}$ & $\begin{array}{c}69.0 \\
(15.0-312.0)\end{array}$ & $75 ; 90 ; 96$ & $4 ; 12 ; 28$ & $\begin{array}{c}96.1 \\
(94.2-98.0)\end{array}$ & $\begin{array}{c}91.2 \\
(85.7-96.7)\end{array}$ \\
\hline $\begin{array}{l}\text { NS1 all } \\
(n=23)\end{array}$ & $\begin{array}{c}76.0 \\
(69.0-81.0)\end{array}$ & $\begin{array}{c}99.0 \\
(98.0-100.0)\end{array}$ & $\begin{array}{c}72.5 \\
(34.3-153.3)\end{array}$ & $\begin{array}{c}0.25 \\
(0.19-0.32)\end{array}$ & $\begin{array}{c}294.0 \\
(129.0-669.0)\end{array}$ & $96 ; 99 ; 100$ & $8 ; 20 ; 43$ & $\begin{array}{c}94.8 \\
(93.7-96.0)\end{array}$ & $\begin{array}{c}85.3 \\
(80.9-89.7)\end{array}$ \\
\hline $\begin{array}{l}\text { NS1 Biorad } \\
(n=14)\end{array}$ & $\begin{array}{c}79.0 \\
(70.0-86.0)\end{array}$ & $\begin{array}{c}100.0 \\
(99.0-100.0)\end{array}$ & $\begin{array}{c}175.2 \\
(54.2-566.1)\end{array}$ & $\begin{array}{c}0.21 \\
(014-0.30)\end{array}$ & $\begin{array}{c}841.0 \\
(254.0-2,783.0)\end{array}$ & $98 ; 99 ; 100$ & $6 ; 17 ; 38$ & $\begin{array}{c}95.9 \\
(94.8-97.1)\end{array}$ & $\begin{array}{c}87.0 \\
(81.7-92.3)\end{array}$ \\
\hline $\begin{array}{l}\text { NS1 others } \\
(n=11)\end{array}$ & $\begin{array}{c}70.0 \\
(61.0-78.0)\end{array}$ & $\begin{array}{c}97.0 \\
(94.0-98.0)\end{array}$ & $\begin{array}{c}21.0 \\
(12.0-36.8)\end{array}$ & $\begin{array}{c}0.31 \\
(0.23-0.41)\end{array}$ & $\begin{array}{c}68.0 \\
(35.0-133.0)\end{array}$ & $88 ; 95 ; 98$ & $9 ; 24 ; 48$ & $\begin{array}{c}91.8 \\
(88.9-94.7)\end{array}$ & $\begin{array}{c}72.2 \\
(58.2-86.1)\end{array}$ \\
\hline $\begin{array}{l}\operatorname{lgM} / \operatorname{lgC} \\
\text { Panbio } \\
(\mathrm{n}=6)\end{array}$ & $\begin{array}{c}56.0 \\
(39.0-72.0)\end{array}$ & $\begin{array}{c}94.0 \\
(86.0-98.0)\end{array}$ & $\begin{array}{c}9.7 \\
(4.1-23.0)\end{array}$ & $\begin{array}{c}0.47 \\
(0.32-0.67)\end{array}$ & $\begin{array}{c}21.0 \\
(8.0-54.0)\end{array}$ & $76 ; 91 ; 97$ & $13 ; 32 ; 58$ & $\begin{array}{c}95.8 \\
(94.0-97.6)\end{array}$ & $\begin{array}{c}95.2 \\
(93.0-97.3)\end{array}$ \\
\hline $\begin{array}{l}\text { NS1/IgM/ } \\
\operatorname{lgG}(n=11)\end{array}$ & $\begin{array}{c}91.0 \\
(84.0-95.0)\end{array}$ & $\begin{array}{c}96.0 \\
(91.0-98.0)\end{array}$ & $\begin{array}{c}20.2 \\
(9.7-42.2)\end{array}$ & $\begin{array}{c}0.10 \\
(0.06-0.17)\end{array}$ & $\begin{array}{c}208.0 \\
(67.0-646.0)\end{array}$ & $87 ; 95 ; 98$ & $3 ; 9 ; 23$ & $\begin{array}{c}93.8 \\
(91.6-96.0)\end{array}$ & $\begin{array}{c}91.4 \\
(88.0-94.7)\end{array}$ \\
\hline
\end{tabular}

95\%Cl: 95\% confidence interval; 12: 12 for heterogeneity; LR: likelihood ratio; PP: positive and negative post-test probabilities assuming dengue prevalence of $25 \%, 50 \%$ and $75 \%$; Sn: sensitivity; Sp: specificity. 
Figure 3

Forest plot for the meta-analysis of rapid immunochromatographic tests (ICT) according to dengue diagnostic analyte.

3a) $\lg \mathrm{A}$

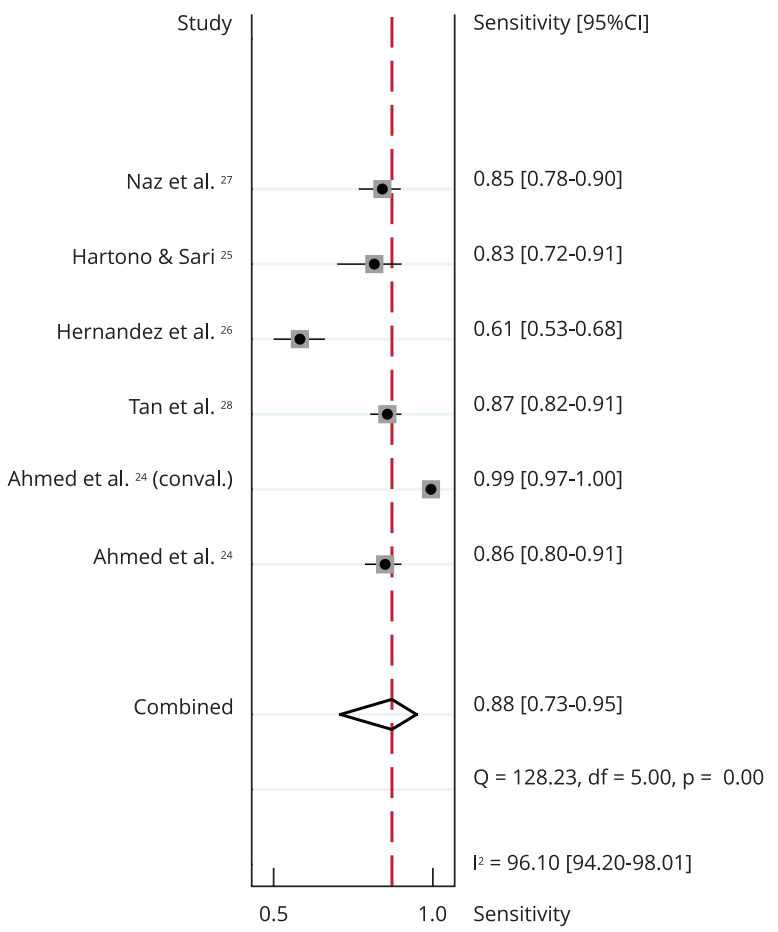

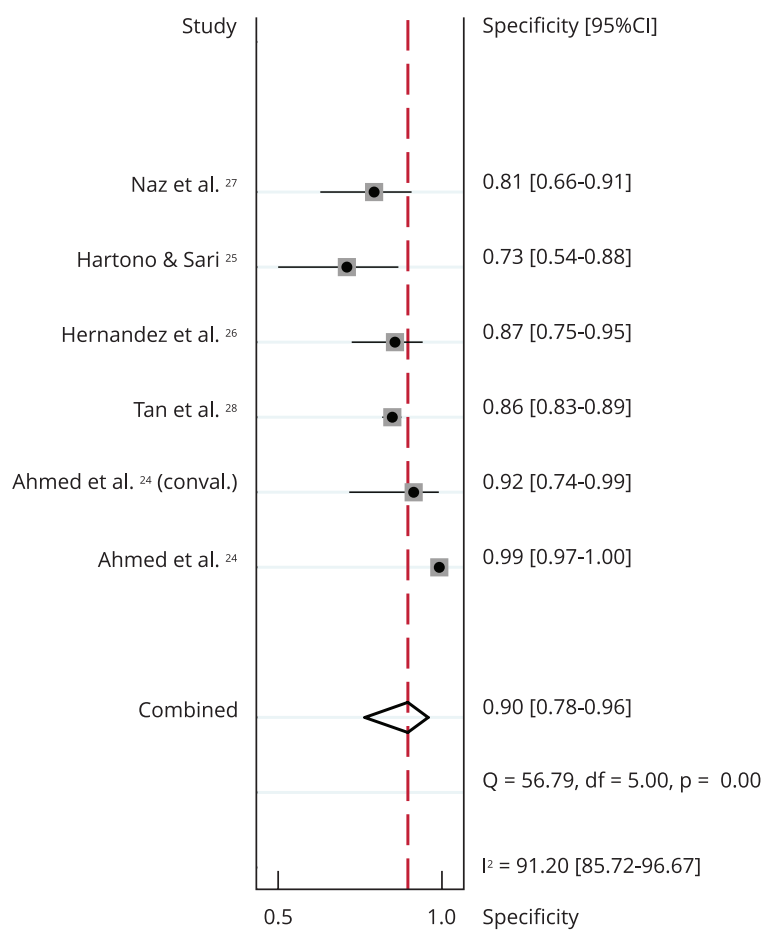

3b) NS1 all tests

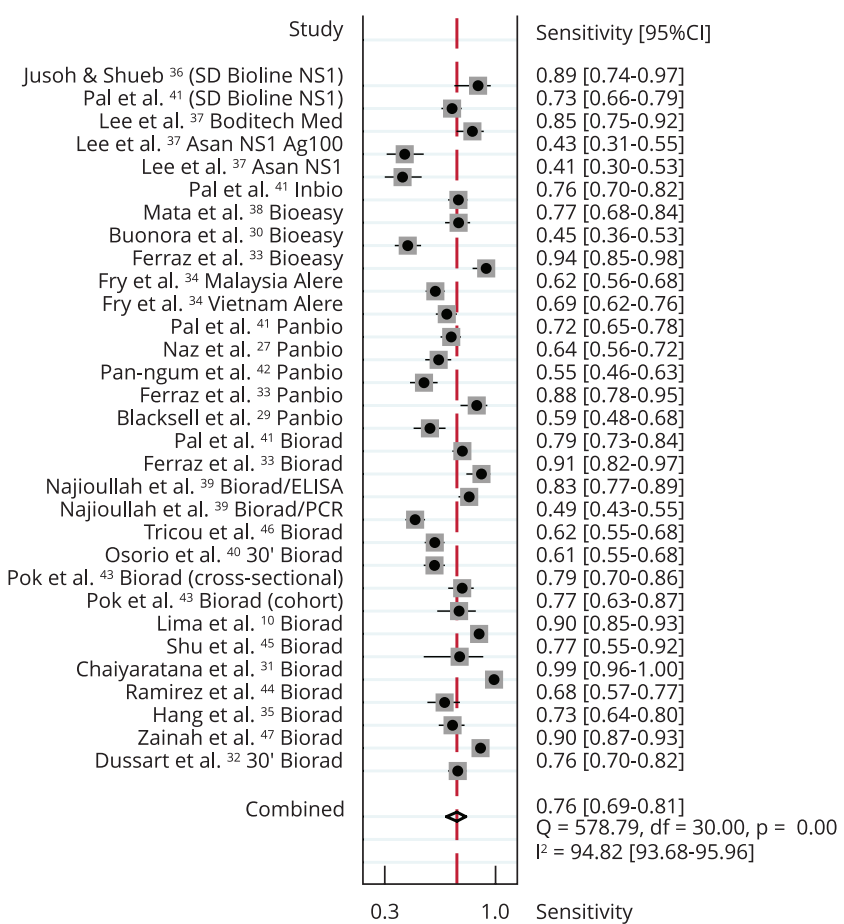

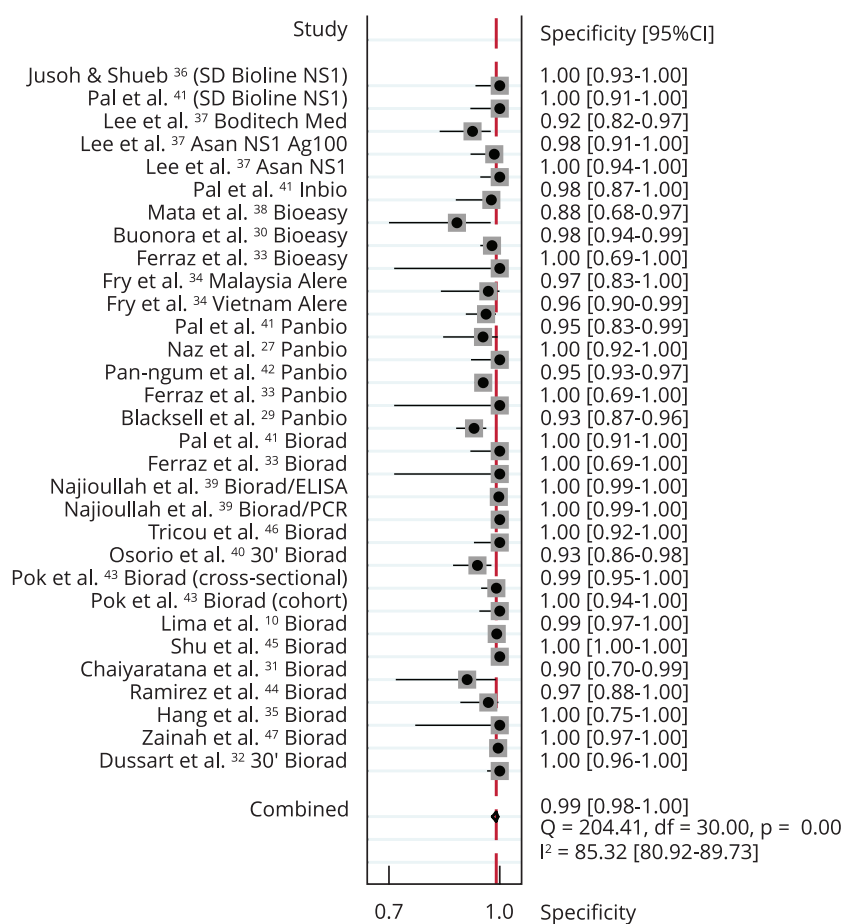

(continues) 
Figure 3 (continued)

3c) IgM/lgG Panbio

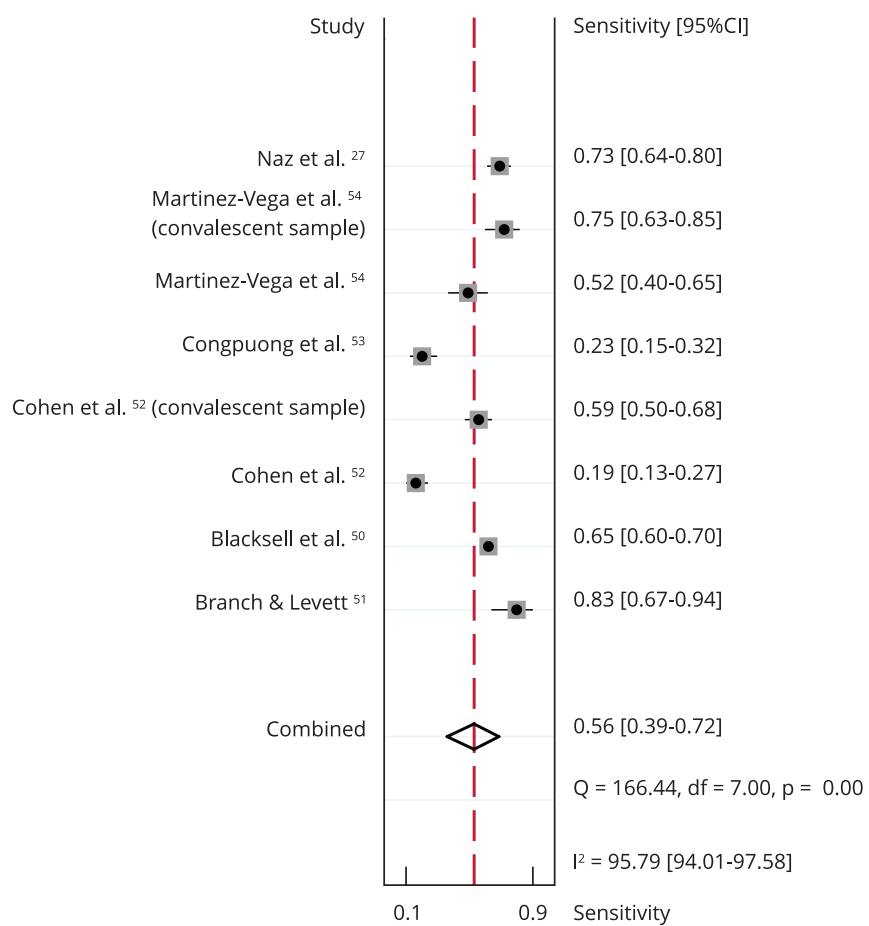

3d) NS1/IgM/lgG.combo test

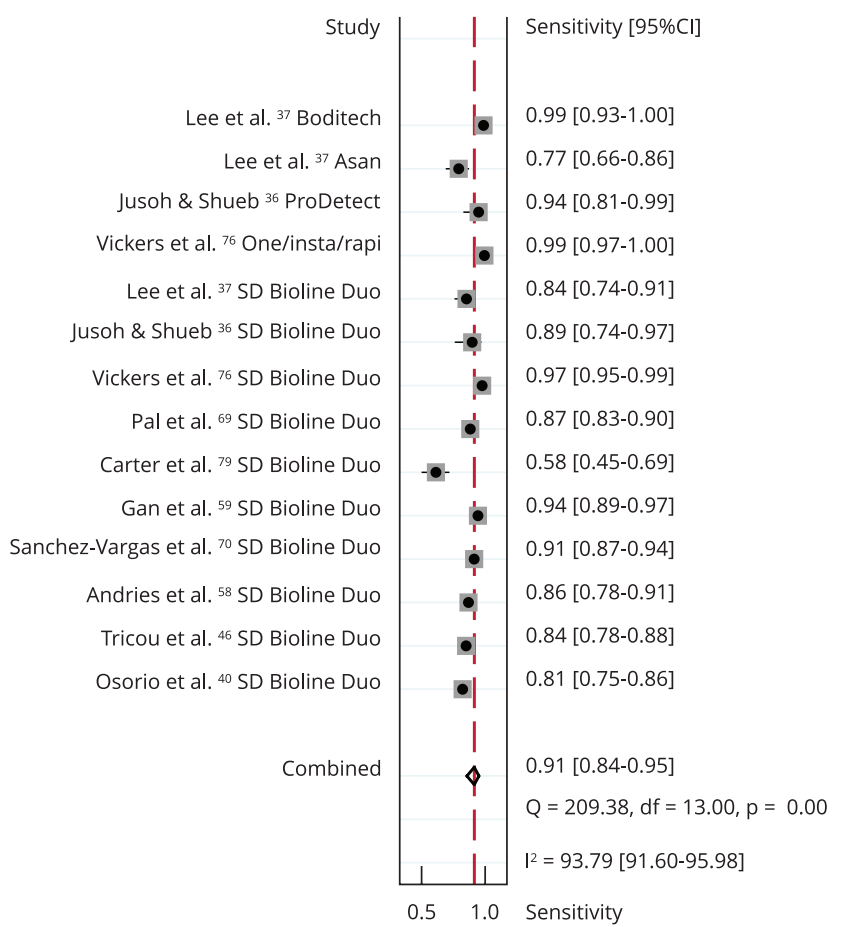

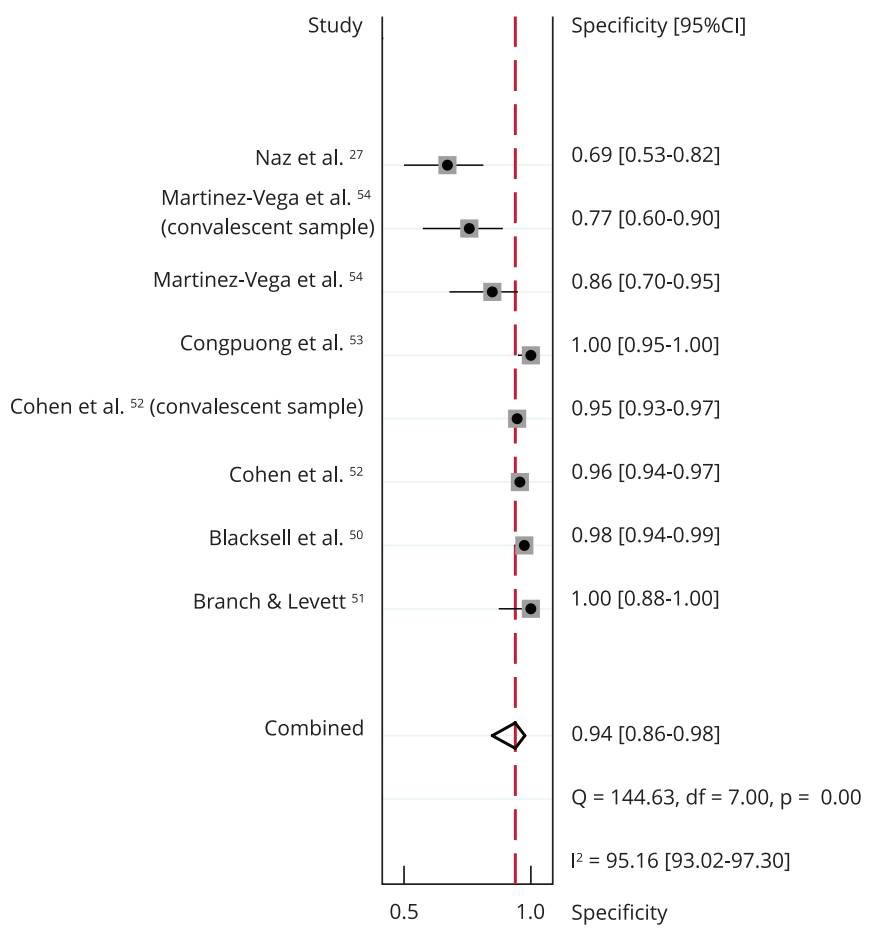

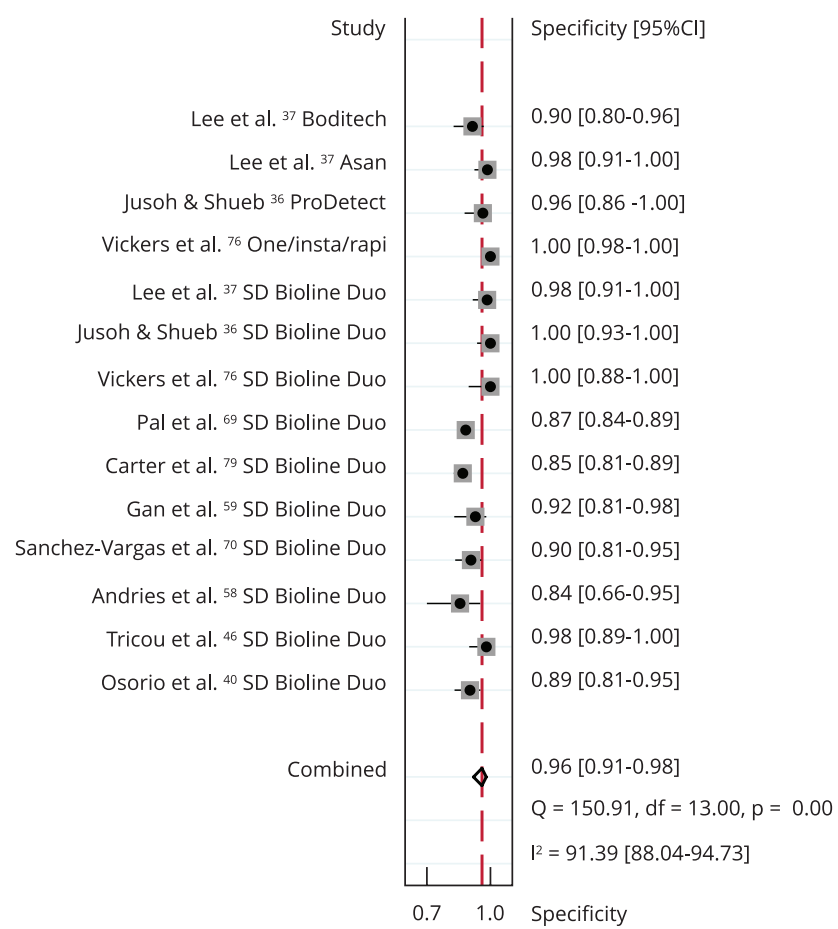

95\% Cl: 95\% confidence interval; conval.: convalescent sample. 
The pooled estimates for all NS1 tests showed sensitivity of 74\%, and higher specificity of $99 \%$. The lower sensitivity values were obtained for NS1 Bioeasy in a Brazilian sample of DENV-4 outbreak 30 as well as for the brand Asan 37.

Bio-Rad Dengue Rapid Test was used for NS1 detection in 14 of the 21 studies 10,31,32,33,35,39,40,41,43, $44,45,46,47,50$ (4,678 samples). Sensitivity ranged from $49.4 \% 39$ to $98.9 \% 31$ and specificity from $91 \% 35$ to $100 \%$ in 8 studies 32,33,35,39,41,43,45,46. The pooled estimate for the Bio-Rad Dengue Rapid Test showed sensitivity of $79 \%$ and specificity of $100 \%$ (Table 2). The post-test probability after a positive result in NS1-based ICT was above 95\% in three different hypothetical scenarios of dengue prevalence of $25 \%, 50 \%$ and $75 \%$.

Several recent studies tested SD Duo Bioline ICT but only showed NS1 results. We opted to describe these on Table 1, but to exclude them from the meta-analyses since there was not blinding of other analyte results in the same cassette.

Assessment of the individual studies did not show publication bias ( $\mathrm{p}$-value $=0.09$ ).

\section{Rapid immunochromatographic tests with IgM/IgG detection}

Seven studies assessed tests with both IgM/IgG detection 27,48,50,51,52,53,54, using 2,597 samples (median 178). Seven studies identified the dengue serotypes, with a total of 251 DENV-1, 176 DENV-2, 193 DENV-3, and 77 DENV-4. Most studies except one evaluating exclusively IgM/IgG ICT were published up to 2011 (Table 1).

These tests presented the lowest values of pooled estimates of sensitivity (54\%), with inadequate values of negative likelihood ratios (NLR > 0.4) (Table 2). Thus, the post-test probabilities after negative results were inconclusive, particularly for epidemic scenarios of prevalence. In the convalescent phase of the disease, the pooled estimate of accuracy showed, as expected, higher sensitivity $(\mathrm{Sn}=$ 62.6\%, 95\%CI: 36.7-82.9), than in the acute phase, 53.8\% (95\%CI: 41.4-65.8), and high specificity in all phases of the disease (94\% and $94.7 \%$,). Specificity was lower for recent studies 27,54 .

Panbio Dengue Duo IgM/IgG was the most widely assessed test, with pooled sensitivity and specificity of $56 \%$ and $90 \%$ (Figure 3 ; Table 2 ).

We detected no publication bias $(\mathrm{p}=0.13)$.

\section{Rapid immunochromatographic tests with simultaneous NS1/IgM/IgG detection}

Ten studies that assessed that type of test included a total of 3,361 patients (median 447) with suspected dengue, with 289 DENV-1, 225 DENV-2, 52 DENV-3 and 39 DENV-4 36,37,40,46,58,59,69,70,77,79 (Table 1).

The best performance was observed for these tests with pooled positive and negative likelihood ratios, of 19.2 and 0.09 , respectively. The post-test probability after negative and positive results in endemic (25\%) and epidemic (75\%) scenarios of dengue prevalence were below 25\% and above $85 \%$, respectively. The pooled estimate of sensitivity was $91 \%$ and specificity, $96 \%$ (Table 2). Carter et al. 79 obtained the poorest performance in sensitivity. After excluding it, the pooled results were unchanged, $\mathrm{Sn}=92 \%(87-95 \%)$ and $\mathrm{Sp}=96 \%(92-98 \%)$.

Some recent studies also reported results for each analyte separately even when testing ICT composed of a cassette with three analytes. We describe these "only results" on Table 1 without including these meta-analyses, since this was only a statistical analysis and not a practical use of a test with a single analyte in a cassette.

We observed no asymmetry in the assessment of publication bias in the studies (p-value $=0.09$ ). 


\section{Discussion}

This was a systematic review addressing the dengue virus detection methods in commercially available ICTs, obtained through a search of nine large databases, with 57 studies included. One strategy used to increase the tests' performance was the simultaneous test of the three analytes NS1, IgM, and $\operatorname{IgG} 40,46,56,58,67,71$. In our review, these ICTs showed high pooled estimates, better than those of IgA ICTs. Among the ICTs with serological detection assessed in this review, those with IgA detection stood out as having the best accuracy, with high pooled sensitivity and specificity in the acute phase compared to IgM/IgG ICT.

IgA tests showed the best performance in triage of patients in acute phase of the disease. They were twice as positive among cases with up to seven days of dengue fever when compared to those in the convalescent phase. Still, these studies did not analyze the tests according to phase of disease (acute/ convalescent), thus making it impossible to claim that this same performance would be maintained in the initial days of the disease.

The current review showed an excellent pooled specificity (99\%-100\%) in the acute phase of the disease in ICTs with exclusive detection of NS1, six times more positive among dengue cases when compared to IgA ICTs during the same phase of the disease. These findings corroborate those of Lima et al. 10, who suggested the best performance of NS1 to confirm dengue cases in the acute phase of disease.

The systematic review published by Alagarasu et al. ${ }^{11}$ assessed IgA ICTs, including three studies with lower estimate sensitivity of $72 \%$ and similar specificity (89\%). However, the wide confidence intervals in the measures of accuracy both in our review and in Alagarasu et al. ${ }^{11}$ make its use for screening questionable.

In recent years, several authors have questioned the use of $\operatorname{IgM} / \operatorname{IgG}$ serology to detect dengue and other flaviviruses, due to the tests' proven cross-reaction with the Zika, yellow fever, and chikungunya viruses, thus limiting their use in scenarios with co-circulation of these viruses 6,80,81.

The systematic review by Zhang et al. 4 showed pooled estimates to these NS1 ICTs similar to our review, with $\mathrm{Sn}=71 \%$ and $\mathrm{Sp}=99 \%$. Both in Zhang et al. 4 and in our review, the performance of NS1 ICT in scenarios with $25 \%, 50 \%$, and $75 \%$ of dengue prevalence pointed to increasing positive post-test probability, ranging from 99 to $100 \%$. When used in screening, these tests should be coupled with a diagnostic algorithm in order to optimize their performance, due to the high number of false-negatives 4 .

The accuracy of IgM/IgG ICTs had the worst performance and studies about this ICT were interrupted in 2014. The systematic review by Blacksell et al. 6 assessed the Panbio ICT in the acute phase of the disease and the summary measures were superior to those in our review. Among other factors, these differences can be attributed to the samples' characteristics related to the convalescent phase or samples with mostly primary infection 6,11 .

Only two studies included in this review reported a potential conflict of interest 31,46. Only one 31 reported sensitivity results that differed from the pooled sensitivity in our review.

In addition to the review's originality, one of its strengths was the scope of the literature search, which included all types of commercially available ICTs for dengue detection, with subgroup analysis according to the ICT detection method in each of the principal commercial ICTs, and when possible, according to the phase of the disease (acute/convalescent).

The review's limitations include the low methodological quality of the included studies and the lack of data for adequate characterization of the samples (27/34, 79.4\%), either by age bracket (21/34, $61.8 \%)$ or dengue serotype $(16 / 34,47.1 \%)$, which prevented such subgroup analyses. Another limitation was the high heterogeneity detected in all the types of ICTs that were assessed, possibly due to the differences between the characteristics of the samples included by the studies. These differences were related to the age of the included patients, predominant type of infection (primary or secondary), serotypes assessed, disease phase assessed by the tests (acute/convalescent), and different reference tests (real-time PCR, RT-PCR, in-house ELISA, MAC-ELISA, among others). This heterogeneity may not be explained by the different reference standards since only three studies did not used at least one test with high specificity (100\% for RT-PCR or ELISA NS1) 10 . Thus, the sensitivity of ICTs does not 
seem to be penalized by the reference standards. Similarly, the almost perfect specificities of ICTs were not influenced by non-optimal sensitivities (89.5\%) of reference tests.

The three systematic reviews that included ICTs pointed to the same limitations described above 4,6,11. Guidelines like the Standards for Reporting Diagnostic Accuracy Studies (STARD) 82 and tools like QUADAS 220 have contributed to the standardization of reporting by accuracy studies, as indicated by Blacksell et al. 83. We emphasize that peer-reviewed journals and regulatory agencies should require the use of both these guidelines in order to assist future reviews and the elaboration of recommendations or protocols. Future studies should investigate cost-effectiveness, decision tree or a combination of multiple tests, including ICT in the diagnostic algorithm.

In conclusion, IgA ICT and NS1/IgM/IgG ICT showed the best pooled performance in the acute phase of dengue. The last one, as suggested by Pal et al. ${ }^{69}$, mainly due to their confirmatory power.

\section{Contributors}

All authors participated in the conception and design of this manuscript and have been involved in either drafting the manuscript or revising it critically for important intellectual content. All authors have given final approval of the final version of this manuscript and agree to be accountable for all aspects of the work.

\section{Additional informations}

ORCID: Verónica Elizabeth Mata (0000-00024203-7608); Carlos Augusto Ferreira de Andrade (0000-0002-0098-4957); Sonia Regina Lambert Passos (0000-0001-9947-2291); Yara Hahr Marques Hökerberg (0000-0001-7140-7172); Levy Vilas Boas Fukuoka (0000-0003-0617-9948); Suzana Alves da Silva (0000-0001-6271-2829).

\section{Acknowledgments}

The study received funding from the Brazilian National Research Council - CNPq (grant $n$. 401396/2013-4; Brazilian Network for Technological and Health Assessment - REBRATS), and Rio de Janeiro State Research Foundation - FAPERJ (grant n. E-25/110.188/2014). Scholarship from FAPERJ (grant n. 221354 E_01/2016] to V.E.M. Grant from CNPq(n. 310765/2016-1) to S.R.L.P. This study was financed in part by the Brazilian National Graduate Studies Board - CAPES (Finance Code 001).

\section{References}

1. Peeling RW, Artsob H, Pelegrino JL, Buchy P, Cardosa MJ, Devi S, et al. Evaluation of diagnostic tests: dengue. Nat Rev Microbiol 2010; 8(12 Suppl):S30-8.

2. Da Costa VG, Marques-Silva AC, Moreli ML. A meta-analysis of the diagnostic accuracy of two commercial NS1 antigen ELISA tests for early dengue virus detection. PLoS One 2014; 9:e94655.

3. San Martin JL, Brathwaite O, Zambrano B, Solorzano JO, Bouckenooghe A, Dayan GH, et al. The epidemiology of dengue in the americas over the last three decades: a worrisome reality. Am J Trop Med Hyg 2010; 82:128-35.

4. Zhang H, Li W, Wang J, Peng H, Che X, Chen $\mathrm{X}$, et al. NS1-based tests with diagnostic utility for confirming dengue infection: a metaanalysis. Int J Infect Dis 2014; 26:57-66.

5. World Health Organization. Dengue guidelines for diagnosis, treatment, prevention and control. Geneva: World Health Organization; 2009.

6. Blacksell SD, Doust JA, Newton PN, Peacock SJ, Day NP, Dondorp AM. A systematic review and meta-analysis of the diagnostic accuracy of rapid immunochromatographic assays for the detection of dengue virus IgM antibodies during acute infection. Trans R Soc Trop Med Hyg 2006; 100:775-84.

7. Gubler DJ. Dengue and dengue hemorrhagic fever. Clin Microbiol Rev 1998; 11:480-96.

8. Passos SRL, Borges dos Santos MA, CerbinoNeto J, Buonora SN, Souza TML, de Oliveira $\mathrm{RVC}$, et al. Detection of Zika virus in April 2013 patient samples, Rio de Janeiro, Brazil. Emerg Infect Dis 2017; 23:2120-1.

9. Campos GS, Bandeira AC, Sardi SI. Zika virus outbreak, Bahia, Brazil. Emerg Infect Dis 2015; 21:1885-6.

10. Lima MRQ, Nogueira RM, Schatzmayr HG, dos Santos FB. Comparison of three commercially available dengue NS1 antigen capture assays for acute diagnosis of dengue in Brazil. PLoS Negl Trop Dis 2010; 4:e738. 
11. Alagarasu K, Walimbe AM, Jadhav SM, Deoshatwar AR. A meta-analysis of the diagnostic accuracy of dengue virus-specific IgA antibody-based tests for detection of dengue infection. Epidemiol Infect 2016; 144:876-86.

12. Lim JK, Alexander N, Di Tanna GL. A systematic review of the economic impact of rapid diagnostic tests for dengue. BMC Health Serv Res 2017; 17:850.

13. Shu PY, Huang JH. Current advances in dengue diagnosis. Clin Diagn Lab Immunol 2004; 11:642-50.

14. Mitra S, Choudhari R, Nori H, Prabhakar AP, Abraham O, Jeyaseelan V, et al. Performance and cost-effectiveness of immunochromatography based rapid diagnostic test (RDT) kits in diagnosis of dengue infection in resource limited set up. Int J Infect Dis 2014; 21 Suppl $1: 450$.

15. Lubell Y, Althaus T, Blacksell SD, Paris DH, Mayxay M, Pan-Ngum W, et al. Modelling the impact and cost-effectiveness of biomarker tests as compared with pathogen-specific diagnostics in the management of undifferentiated fever in remote tropical settings. PLoS One 2016; 11:e0152420.

16. Andries AC, Duong V, Ong S, Ros S, Sakuntabhai A, Horwood P, et al. Evaluation of the performances of six commercial kits designed for dengue NS1 and anti-dengue $\operatorname{IgM}$, IgG and IgA detection in urine and saliva clinical specimens. BMC Infect Dis 2016; 16:201.

17. Musso D, Roche C, Nhan TX, Robin E, Teissier A, Cao-Lormeau VM. Detection of Zika virus in saliva. J Clin Virol 2015; 68:53-5.

18. Colonetti T, Rocha BVE, Grande AJ, Alexandre MCM, Dondossola ER, Madeira K, et al. Accuracy of immunoglobulin $\mathrm{M}$ and immunoglobulin A of saliva in early diagnosis of dengue: systematic review and meta-analysis. An Acad Bras Ciênc 2018; 90:3147-54.

19. Liberati A, Altman DG, Tetzlaff J, Mulrow C, Gotzsche PC, Ioannidis JP, et al. The PRISMA statement for reporting systematic reviews and meta-analyses of studies that evaluate health care interventions: explanation and elaboration. J Clin Epidemiol 2009; 62:e1-34.

20. Whiting PF, Rutjes AW, Westwood ME, Mallett S, Deeks JJ, Reitsma JB, et al. QUADAS-2: a revised tool for the quality assessment of diagnostic accuracy studies. Ann Intern Med 2011; 155:529-36

21. Higgins JP, Thompson SG, Deeks JJ, Altman DG. Measuring inconsistency in meta-analyses. BMJ 2003; 327:557-60.

22. DerSimonian R, Laird N. Meta-analysis in clinical trials. Control Clin Trials 1986; 7:177-88.

23. Deeks JJ, Macaskill P, Irwig L. The performance of tests of publication bias and other sample size effects in systematic reviews of diagnostic test accuracy was assessed. J Clin Epidemiol 2005; 58:882-93.

24. Ahmed F, Mursalin H, Alam MT, Amin R, Sekaran SD, Wang SM, et al. Evaluation of ASSURE(R) Dengue IgA Rapid Test using dengue-positive and dengue-negative samples. Diagn Microbiol Infect Dis 2010; 68:339-44.
25. Hartono A, Sari SK. Diagnosis of dengue virus infection with IgA anti-dengue rapid tests. Int J Infect Dis 2012; 16 Suppl:e317-473.

26. Hernandez SIC, Gonzalez Mateos S, Flores Aguilar H, Lopez Martinez I, Alpuche Aranda C, Ludert JE, et al. Evaluation of a novel commercial rapid test for dengue diagnosis based on specific IgA detection. Diagn Microbiol Infect Dis 2012; 72:150-5.

27. Naz A, Zahid D, Murky SN, Nadeem M, Sil BK, Shamsi TS. Evaluation of efficacy of various immunochromatographic rapid tests for dengue diagnosis. Pak J Med Sci 2014; 30:166-71.

28. Tan YY, Sekaran SD, Wang SM, Ahmed F, Hossain A, Sil BK. Development of ASSURE Dengue IgA Rapid Test for the detection of antidengue IgA from dengue infected patients. J Glob Infect Dis 2011; 3:233-40.

29. Blacksell SD, Jarman RG, Bailey MS, Tanganuchitcharnchai A, Jenjaroen K, Gibbons RV, et al. Evaluation of six commercial point-ofcare tests for diagnosis of acute dengue infections: the need for combining NS1 antigen and IgM/IgG antibody detection to achieve acceptable levels of accuracy. Clin Vaccine Immunol 2011; 18:2095-101.

30. Buonora SN, Passos SR, do Carmo CN, Quintela FM, de Oliveira DN, dos Santos FB, et al. Accuracy of clinical criteria and an immunochromatographic strip test for dengue diagnosis in a DENV-4 epidemic. BMC Infect Dis 2016; $16: 37$.

31. Chaiyaratana W, Chuansumrit A, Pongthanapisith V, Tangnararatchakit K, Lertwongrath S, Yoksan S. Evaluation of dengue nonstructural protein 1 antigen strip for the rapid diagnosis of patients with dengue infection. Diagn Microbiol Infect Dis 2009; 64:83-4.

32. Dussart P, Petit L, Labeau B, Bremand L, Leduc A, Moua D, et al. Evaluation of two new commercial tests for the diagnosis of acute dengue virus infection using NS1 antigen detection in human serum. PLoS Negl Trop Dis 2008; 2:e280.

33. Ferraz FO, Bomfim MR, Totola AH, Avila TV, Cisalpino D, Pessanha JE, et al. Evaluation of laboratory tests for dengue diagnosis in clinical specimens from consecutive patients with suspected dengue in Belo Horizonte, Brazil. J Clin Virol 2013; 58:41-6.

34. Fry SR, Meyer M, Semple MG, Simmons CP, Sekaran SD, Huang JX, et al. The diagnostic sensitivity of dengue rapid test assays is significantly enhanced by using a combined antigen and antibody testing approach. PLoS Negl Trop Dis 2011; 5:e1199.

35. Hang VT, Nguyet NM, Trung DT, Tricou V, Yoksan S, Dung NM, et al. Diagnostic accuracy of NS1 ELISA and lateral flow rapid tests for dengue sensitivity, specificity and relationship to viraemia and antibody responses. PLoS Negl Trop Dis 2009; 3:e360.

36. Jusoh TNAM, Shueb RH. Performance evaluation of commercial dengue diagnostic tests for early detection of dengue in clinical samples. J Trop Med 2017; 2017:4687182. 
37. Lee H, Ryu JH, Park HS, Park KH, Bae H, Yun $\mathrm{S}$, et al. Comparison of six commercial diagnostic tests for the detection of dengue virus non-structural-1 antigen and $\operatorname{IgM} / \operatorname{IgG}$ antibodies. Ann Lab Med 2019; 39:566-71.

38. Mata VE, Passos SRL, Hökerberg YHM, Berardinelli GM, Dos Santos MAB, Fukuoka LVB, et al. Accuracy and reliability of an NS1 rapid immunochromatographic test for DENV-1 diagnosis at point of care and in the laboratory. BMC Infect Dis 2017; 17:594.

39. Najioullah F, Combet E, Paturel L, Martial J, Koulmann L, Thomas L, et al. Prospective evaluation of nonstructural 1 enzyme-linked immunosorbent assay and rapid immunochromatographic tests to detect dengue virus in patients with acute febrile illness. Diagn Microbiol Infect Dis 2011; 69:172-8.

40. Osorio L, Ramirez M, Bonelo A, Villar LA, Parra B. Comparison of the diagnostic accuracy of commercial NS1-based diagnostic tests for early dengue infection. Virol J 2010; 7:361.

41. Pal S, Dauner AL, Mitra I, Forshey BM, Garcia P, Morrison AC, et al. Evaluation of dengue NS1 antigen rapid tests and ELISA kits using clinical samples. PLoS One 2014; 9:e113411.

42. Pan-ngum W, Blacksell SD, Lubell Y, Pukrittayakamee S, Bailey MS, de Silva HJ, et al. Estimating the true accuracy of diagnostic tests for dengue infection using bayesian latent class models. PLoS One 2013; 8:e50765.

43. Pok KY, Lai YL, Sng J, Ng LC. Evaluation of nonstructural 1 antigen assays for the diagnosis and surveillance of dengue in Singapore. Vector Borne Zoonotic Dis 2010; 10:1009-16.

44. Ramirez AH, Moros Z, Comach G, Zambrano J, Bravo L, Pinto B, et al. Evaluation of dengue NS1 antigen detection tests with acute sera from patients infected with dengue virus in Venezuela. Diagn Microbiol Infect Dis 2009; 65:247-53.

45. Shu PY, Yang CF, Kao JF, Su CL, Chang SF, Lin $\mathrm{CC}$, et al. Application of the dengue virus NS1 antigen rapid test for on-site detection of imported dengue cases at airports. Clin Vaccine Immunol 2009; 16:589-91.

46. Tricou V, Vu HT, Quynh NV, Nguyen CV, Tran HT, Farrar J, et al. Comparison of two dengue NS1 rapid tests for sensitivity, specificity and relationship to viraemia and antibody responses. BMC Infect Dis 2010; 10:142.

47. Zainah S, Wahab AH, Mariam M, Fauziah MK, Khairul AH, Roslina I, et al. Performance of a commercial rapid dengue NS1 antigen immunochromatography test with reference to dengue NS1 antigen-capture ELISA. J Virol Methods 2009; 155:157-60.

48. Aikat A, Sarkar A, Tudu N, Moitra S, Pal PP, Sarkar TK. Diagnostic dilemma of dengue fever: how much reliability are there in rapidity. J Indian Med Assoc 2011; 109:543-5.

49. Berry N, Chakravarti A, Gur R, Mathur MD. Serological investigation of a febrile outbreak in Delhi, India, using a rapid immunochromatographic test. J Clin Microbiol 1998; 36:2795-6.
50. Blacksell SD, Newton PN, Bell D, Kelley J Mammen Jr. MP, Vaughn DW, et al. The comparative accuracy of 8 commercial rapid immunochromatographic assays for the diagnosis of acute dengue virus infection. Clin Infect Dis 2006; 42:1127-34.

51. Branch SL, Levett PN. Evaluation of four methods for detection of immunoglobulin $\mathrm{M}$ antibodies to dengue virus. Clin Diagn Lab Immunol 1999; 6:555-7.

52. Cohen AL, Dowell SF, Nisalak A, Mammen Jr. MP, Petkanchanapong W, Fisk TL. Rapid diagnostic tests for dengue and leptospirosis: antibody detection is insensitive at presentation. Trop Med Int Health 2007; 12:47-51.

53. Congpuong K, Chuchan S, Kwangthong S, Kangchaingone Y, Darakapong A. Appropriate laboratory tests for the diagnosis of dengue infection at a general hospital in Southern Thailand. Asian Biomed (Res Rev News) 2008; 2:289-95.

54. Martinez-Vega RA, Diaz-Quijano FA, Coronel-Ruiz C, Yebrail Gomez S, Villar-Centeno LA. Evaluation of PANBIO rapid immunochromatographic cassette for dengue diagnosis in a Colombian endemic area. Biomedica 2009; 29:616-24.

55. Nga TTT, Thai KTD, Phuong HL, Giao PT, Hung LQ, Binh TQ, et al. Evaluation of two rapid immunochromatographic assays for diagnosis of dengue among Vietnamese febrile patients. Clin Vaccine Immunol 2007; 14:799801.

56. Pun R, Shah Y, Gupta GP, Sherchand SP, Pandey BD. Prognostic value of rapid test for diagnosis of dengue in Nepalese patients during 2010 epidemic. Kathmandu Univ Med J (KUMJ) 2012; 10:7-10.

57. Yusuf NW, Kausar N, Akbar R, Iqbal N. Comparison of diagnostic efficacy of rapid diagnostic devices for dengue virus infection: a piolt study. J Ayub Med Coll Abbottabad 2008; 20:26-8.

58. Andries AC, Duong V, Ngan C, Ong S, Huy R, Sroin KK, et al. Field evaluation and impact on clinical management of a rapid diagnostic kit that detects dengue NS1, IgM and IgG. PLoS Negl Trop Dis 2012; 6:e1993.

59. Gan VC, Tan LK, Lye DC, Pok KY, Mok SQ, Chua RC, et al. Diagnosing dengue at the point-of-care: utility of a rapid combined diagnostic kit in Singapore. PLoS One 2014; 9:e90037.

60. Garg A, Garg J, Singh DV, Dhole TN. Can rapid dengue diagnostic kits be trusted? A comparative study of commercially available rapid kits for serodiagnosis of dengue fever. J Lab Physicians 2019; 11:63-7.

61. Huits R, Soentjens P, Maniewski-Kelner U, Theunissen C, Van Den Broucke S, Florence E, et al. Clinical utility of the nonstructural 1 antigen rapid diagnostic test in the management of dengue in returning travelers with fever. Open Forum Infect Dis 2017; 4:ofw273. 
62. Hunsperger EA, Sharp TM, Lalita P, Tikomaidraubuta K, Cardoso YR, Naivalu T, et al. Use of a rapid test for diagnosis of dengue during suspected dengue outbreaks in resource-limited regions. J Clin Microbiol 2016; 54:2090-5.

63. Jang WS, Kwak SY, May WL, Yang DJ, Nam J, Lim CS. Comparative evaluation of three dengue duo rapid test kits to detect NS1, IgM, and IgG associated with acute dengue in children in Myanmar. PLoS One 2019; 14:e0213451.

64. Kikuti M, Cruz JS, Rodrigues MS, Tavares AS, Paploski IAD, Silva MMO, et al. Accuracy of the SD BIOLINE Dengue Duo for rapid pointof-care diagnosis of dengue. PLoS One 2019; 14:e0213301.

65. Krishnananthasivam S, Fernando AN, Tippalagama R, Tennekoon R, Man JD, Seneviratne $\mathrm{D}$, et al. Evaluation of a commercial rapid test kit for detection of acute dengue infection. Southeast Asian J Trop Med Public Health 2015; 46:602-10.

66. Kyaw AK, Ngwe Tun MM, Naing ST, Htet KKK, Htwe TT, Khaing YY, et al. Evaluation of commercially available three dengue rapid diagnostic test kits for diagnosis of acute dengue virus infection at the point-of-care setting in Myanmar. J Virol Methods 2019; 273:113724.

67. Parham LA, Sánchez C, López MJ, Lorenzana I. Evaluation of two parameters for dengue diagnosis in Honduran patients. Am J Trop Med Hyg 2014; 91(5 Suppl 1):429.

68. Liu LT, Dalipanda T, Jagilly R, Wang YH, Lin PC, Tsai CY, et al. Comparison of two rapid diagnostic tests during a large dengue virus serotype 3 outbreak in the Solomon Islands in 2013. PLoS One 2018; 13:e0202304.

69. Pal S, Dauner AL, Valks A, Forshey BM, Long KC, Thaisomboonsuk B, et al. Multicountry prospective clinical evaluation of two enzymelinked immunosorbent assays and two rapid diagnostic tests for diagnosing dengue fever. J Clin Microbiol 2015; 53:1092-102.

70. Sanchez-Vargas LA, Sanchez-Marce EE, Vivanco-Cid H. Evaluation of the SD BIOLINE Dengue Duo rapid test in the course of acute and convalescent dengue infections in a Mexican endemic region. Diagn Microbiol Infect Dis 2014; 78:368-72.

71. Sandoval JJV, Amores DR, Ramudo SV, Gutiérrez NC, Tirado MGG. Evaluation of the SD Dengue Duo diagnosis system for detection of NS1 protein and IgM and IgG dengue antibodies. Rev Cubana Med Trop 2012; 64:27-34.

72. Shih HI, Hsu HC, Wu CJ, Lin CH, Chang CM, Tu YF, et al. Applications of a rapid and sensitive Dengue DUO Rapid Immunochromatographic Test kit as a diagnostic strategy during a dengue type 2 epidemic in an urban city. PLoS One 2016; 11:e0158437.

73. Shukla MK, Singh N, Sharma RK, Barde PV. Utility of dengue NS1 antigen rapid diagnostic test for use in difficult to reach areas and its comparison with dengue NS1 ELISA and qRTPCR. J Med Virol 2017; 89:1146-50.
74. Simonnet C, Okandze A, Matheus S, Djossou F, Nacher M, Mahamat A. Prospective evaluation of the SD BIOLINE Dengue Duo rapid test during a dengue virus epidemic. Eur J Clin Microbiol Infect Dis 2017; 36:2441-7.

75. Tontulawat P, Pongsiri P, Thongmee C, Theamboonlers A, Kamolvarin N, Poovorawan Y. Evaluation of rapid immunochromatographic NS1 test, anti-dengue IgM test, semi-nested PCR and IgM ELISA for detection of dengue virus. Southeast Asian J Trop Med Public Health 2011; 42:570-8.

76. Vickers I, Harvey K, Nelson K, Brown M, Bullock-DuCasse M, Lindo J. Evaluation of OneStep Dengue NS1 RapiDip InstaTest and OneStep Dengue Fever IgG/IgM RapiCard InstaTest during the course of a dengue type 1 epidemic. Diagn Microbiol Infect Dis 2017; 89:271-5.

77. Vickers IE, Harvey KM, Brown MG, Nelson $\mathrm{K}$, DuCasse MB, Lindo JF. The performance of the SD BIOLINE Dengue DUO(R) rapid immunochromatographic test kit for the detection of NS1 antigen, IgM and IgG antibodies during a dengue type 1 epidemic in Jamaica. J Biomed Sci 2015; 22:55.

78. Prado PS, Almeida Junior JTD, Abreu LT, Silva CG, Souza LDC, Gomes MC, et al. Validation and reliability of the rapid diagnostic test 'SD Bioeasy Dengue Duo' for dengue diagnosis in Brazil: a phase III study. Mem Inst Oswaldo Cruz 2018; 113:e170433.

79. Carter MJ, Emary KR, Moore CE, Parry CM, Sona S, Putchhat $\mathrm{H}$, et al. Rapid diagnostic tests for dengue virus infection in febrile Cambodian children: diagnostic accuracy and incorporation into diagnostic algorithms. PLoS Negl Trop Dis 2015; 9:e0003424.

80. Dejnirattisai W, Supasa P, Wongwiwat W, Rouvinski A, Barba-Spaeth G, Duangchinda T, et al. Dengue virus sero-cross-reactivity drives antibody-dependent enhancement of infection with zika virus. Nat Immunol 2016; 17:1102-8.

81. Steinhagen K, Probst C, Radzimski C, Schmidt-Chanasit J, Emmerich P, van Esbroeck M, et al. Serodiagnosis of Zika virus (ZIKV) infections by a novel NS1-based ELISA devoid of cross-reactivity with dengue virus antibodies: a multicohort study of assay performance, 2015 to 2016. Euro Surveill 2016; 21:30426.

82. Cohen JF, Korevaar DA, Altman DG, Bruns DE, Gatsonis CA, Hooft L, et al. STARD 2015 guidelines for reporting diagnostic accuracy studies: explanation and elaboration. BMJ Open 2016; 6:e012799.

83. Blacksell SD. Commercial dengue rapid diagnostic tests for point-of-care application: recent evaluations and future needs? J Biomed Biotechnol 2012; 2012:151967. 


\section{Resumo}

A dengue é uma importante arbovirose em termos de morbidade, mortalidade, impacto econômico e controle do vetor. Os testes de referência são dispendiosos e demorados e exigem pessoal capacitado. A prevenção das complicações da dengue com o diagnóstico rápido tem tomado como base a testagem com métodos imunocromatográficos (ICT). $O$ estudo é uma revisão sistemática e meta-análise da acurácia diagnóstica de estudos de ICT de IgA, NS1, IgM e/ou IgG em casos suspeitos de dengue aguda ou convalescente, usando uma combinação de RT-PCR, ELISA NS1, IgM IgG ou isolamento viral como padrão de referência. O projeto foi registrado na base PROSPERO (CRD42014009885). Dois pares de revisores realizaram as buscas nas bases de dados PubMed, BIREME, Science Direct, Scopus, Web of Science, Ovid MEDLINE JBrigs, SCIRUS e EMBASE, além da seleção, extração e avaliação de qualidade com a ferramenta QUADAS 2. A partir de 3.783 estudos, selecionamos 57, dos quais 40 foram incluídos nas meta-análises de acordo com o analito testado, com alta heterogeneidade (I2 > 90\%), conforme esperado para testes diagnósticos. Foi detectada a maior sensibilidade conjunta no IgA de fase aguda (92,8\%), com excelente especificidade (90\%). A meta-análise de ICT com NS1/IgM/IgG mostrou sensibilidade de $91 \%$ e especificidade de 96\%. O pior desempenho para triagem foi com o ICT de IgM/IgG (sensibilidade $=56 \%$ ). Portanto, os estudos de ICT com NS1/IgM/IgG mostraram o melhor desempenho combinado na fase aguda da doença.

Dengue; Diagnóstico; Sensibilidade e

Especificidade; Revisão Sistemática; Metanálise

\section{Resumen}

El dengue es una importante enfermedad arboviral, en términos de morbilidad, mortalidad, impacto económico y desafíos en el control del vector. Las mejores prácticas son caras, consumen mucho tiempo y requieren personal formado. Prevenir las complicaciones del dengue con un rápido diagnóstico se ha basado en pruebas con métodos inmunocromatográficos optimizados fáciles de realizar (ICT por sus siglas en inglés). Se trata de una revisión sistemática de metaanálisis sobre la precisión diagnóstica de estudios de IgA, NS1, IgM y/o IgG ICT en casos sospechosos de fases agudas o convalecientes de dengue, usando la combinación de RT-PCR, ELISA NS1, IgM IgG o el aislamiento viral como referencia estándar. Este proyecto se registró en PROSPERO (CRD42014009885). Dos parejas de revisores investigaron en las bases de datos de: PubMed, BIREME, Science Direct, Scopus, Web of Science, Ovid MEDLINE JBrigs, SCIRUS y EMBASE, seleccionaron, extrajeron, y realizaron la evaluación de calidad mediante QUADAS 2. De 3.783 estudios, se seleccionaron 57 , de los cuales 40 fueron metaanálisis, según el analito probado, con una alta heterogeneidad (I2 > 90\%), como se esperaba en las pruebas de diagnóstico. Detectamos una sensibilidad más alta combinada en la fase aguda IgA (92.8\%) con una excelente (90\%) especificidad. Los metaanálisis ICT con NS1/IgM/IgG mostraron un 91\% de sensibilidad y un $96 \%$ de especificidad. Se produjo un rendimiento más pobre en el diagnóstico IgM/ IgG ICT (sensibilidad $=56 \%$ ). De este modo, los estudios con NS1/IgM/IgG ICT mostraron un rendimiento mejor combinado en la fase aguda de la enfermedad.

Dengue; Diagnóstico; Sensibilidad y

Especificidad; Revisión Sistemática; Metaanálisis
Submitted on 25/Nov/2018

Final version resubmitted on 30/Jan/2020

Approved on 18/Feb/2020 